Research Paper

\title{
The role of uncertainty in bedrock depth and hydraulic properties on the stability of a variably-saturated slope
}

\author{
Guilherme J.C. Gomes ${ }^{\mathrm{a}, \mathrm{b}}$, Jasper A. Vrugt ${ }^{\mathrm{b}, \mathrm{c}}$, Eurípedes A. Vargas Jr. ${ }^{\mathrm{a}, *}$, Julia T. Camargo ${ }^{\mathrm{d}}$, Raquel Q. Velloso ${ }^{\mathrm{a}}$, \\ Martinus Th. van Genuchten ${ }^{\mathrm{e}, \mathrm{f}}$
}

a Department of Civil Engineering, Pontifical Catholic University of Rio de Janeiro, Rio de Janeiro, Brazil

${ }^{\mathrm{b}}$ Department of Civil and Environmental Engineering, University of California, Irvine, CA, USA

${ }^{\mathrm{c}}$ Department of Earth System Science, University of California, Irvine, CA, USA

${ }^{\mathrm{d}}$ Department of Civil and Environmental Engineering, Stanford University, Stanford, CA, USA

${ }^{\mathrm{e}}$ NIDES Interdisciplinary Center for Social Development, Federal University of Rio de Janeiro, Rio de Janeiro, Brazil

${ }^{\mathrm{f}}$ Department of Earth Sciences, Utrecht University, Utrecht, The Netherlands

\section{A R T I C L E I N F O}

\section{Article history:}

Received 30 November 2016

Received in revised form 16 February 2017

Accepted 22 March 2017

Available online 6 April 2017

\section{Keywords:}

Bedrock depth

Hydraulic parameters

Slope stability

Unsaturated flow

Limit analysis

Safety factor

\begin{abstract}
A B S T R A C T
We investigate the uncertainty in bedrock depth and soil hydraulic parameters on the stability of a variably-saturated slope in Rio de Janeiro, Brazil. We couple Monte Carlo simulation of a threedimensional flow model with numerical limit analysis to calculate confidence intervals of the safety factor using a 22-day rainfall record. We evaluate the marginal and joint impact of bedrock depth and soil hydraulic uncertainty. The mean safety factor and its $95 \%$ confidence interval evolve rapidly in response to the storm events. Explicit recognition of uncertainty in the hydraulic properties and depth to bedrock increases significantly the probability of failure.
\end{abstract}

(c) 2017 Elsevier Ltd. All rights reserved.

\section{Introduction}

Hilly landscapes are typically mantled with soil and underlain by a weathered bedrock zone that may extend tens of meters beneath the surface before reaching fresh bedrock [1]. The design, construction, and maintenance of buildings, infrastructure, and other man-made structures in such environments depends critically on the stability of the soil and underlying bedrock. It is well-known that precipitation exerts a strong control on hillslope stability via infiltrating water, which elevates pore pressures within the soil mantle and reduces the shear strength. Thus, the more water is stored in the soil mantle, the more susceptible a hillslope is to landsliding. Numerous contributions to the geotechnical literature have investigated the triggering mechanisms and probability of occurrence of rainfall-induced landslides. This body of work has shown that the stability of hillslopes is controlled by

\footnotetext{
* Corresponding author.

E-mail addresses: guilhermejcg@yahoo.com.br (G.J.C. Gomes), jasper@uci.edu (J.A. Vrugt), vargas@puc-rio.br (E.A. Vargas Jr.), juliatcamargo@gmail.com (J.T. Camargo), raquelvelloso@puc-rio.br (R.Q. Velloso), rvangenuchten@hotmail. com (M.Th. van Genuchten).
}

many different factors including surface topography [2], depth to unweathered bedrock [3-6], the hydraulic properties [7,8] and shear strength [9-11] including their spatial variability [12,13].

The stability of a hillslope is commonly characterized by a single integrated measure of its load carrying capacity. This measure, coined the factor of safety or safety factor (SF), requires detailed computational analysis since field experiments are often impractical, time-consuming, labor-intensive and expensive. Many different methods have been developed in the geotechnical literature to compute the SF of a slope, ranging from simplified infinite slope approaches to more advanced limit equilibrium methods and sophisticated numerical procedures. These methods differ in their underlying assumptions and rigor, and consequently, may provide conflicting results. Slope stability analyses are further complicated by our inability to characterize adequately the hillslope interior. Indeed, soil properties and/or related variables deemed necessary for the different methods cannot be measured in the field with infinite precision, and consequently, the computed SF values are subject to considerable uncertainty [14].

Conventional (deterministic) methods for slope stability analyses calculate the SF without recourse to the underlying uncertainty in soil and hillslope properties $[15,16]$. Probabilistic methods allow 
designers to address issues beyond those that can be dealt with using deterministic methods. Such methods allow us to calculate confidence intervals of the SF due to uncertainty in soil properties and stratigraphic conditions, data errors, and model structural inadequacies $[15,17]$. The impact of uncertainty in the soil properties on the SF is relatively easily quantified using statistical methods [15], and has been explored by different authors [7,9,11,18,19]. This includes treatment of uncertainty in the porosity [20], specific weight [11,17], cohesion [11,17], and friction angle [11,17] of the soil mantle, and the spatial variability of the hydraulic conductivity $[7,20]$. Data errors arise from improper, incomplete and/or inaccurate measurement methods [15]. For example, the subsurface stratigraphy can exhibit considerable spatial variability, which, if poorly characterized, compromises the accuracy of slope stability studies $[3,4]$. What is more, spatiotemporal variability of the moisture content and distribution of the hillslope interior controls slope stability, yet is difficult to characterize adequately with porous flow simulators due to large uncertainties in the hydraulic properties and boundary conditions of the considered soil-bedrock domain [15,21].

Geotechnical stability analyses under transient soil-water conditions require knowledge of the soil hydraulic properties, namely the water retention function (or soil-water characteristic curve, SWCC) and the unsaturated soil hydraulic conductivity function, HCF. These two constitutive relationships generally exhibit considerable spatial variability, and are very time consuming, labor intensive, and costly to measure at the scale of a hillslope [22,23]. Whereas several authors have investigated the effect of the saturated hydraulic conductivity on slope (in) stability [12,24-26], relatively few contributions in the geotechnical literature have explored properly the coordinated impact of SWCC and HCF uncertainty on the SF values derived from slope stability studies $[4,6,18,27]$. We agree wholeheartedly with Liang and Uchida [23] that a detailed characterization of the temporal and spatial variability of the moisture content of the soil mantle is warranted in slope stability studies. Such studies should also include proper recognition of uncertainty in the soil hydraulic properties [8].

Liang and Uchida [23] evaluated, in a recent study, the impact of soil hydraulic parameter uncertainty on distributed moisture contents simulated with a three-dimensional variably-saturated flow model. Using a detailed depth to bedrock map of a small catchment in Japan and different parametrizations of the soil hydraulic functions, these authors found that saturation develops predominantly at the soil-bedrock interface. The bedrock surface connects sparsely saturated regions [28], and thus determines, along with regolith thickness, the water pressure within the soil mantle's pores. Indeed, depth to bedrock is a key variable that controls subsurface flow [29], and triggers landslides during rainfall events [30-32].

As hillslope interiors are costly, labor-intensive, and difficult to access, most slope stability studies use a relatively simple description of the bedrock surface $[3,6,7,11]$. Resulting topographic maps often do not do justice to complex field measurements of the bedrock depth, which often demonstrate significant spatial variability $[3,33]$ with a geometry that is difficult to characterize adequately with some closed-form mathematical expression, while hydraulic and strength parameters can vary abruptly at the soil-bedrock interface. Whereas some authors have used high-resolution bedrock depth maps to assess hillslope stability [28,32,34,35], existing studies in the literature do not properly recognize the effect of bedrock depth uncertainty on slope stability assessments.

The purpose of the present study is to evaluate the marginal and joint impact of bedrock depth and hydraulic uncertainty on the stability and probability of failure of a natural soil-mantled hillslope in Rio de Janeiro, Brazil. The soils in our experimental watershed are unsaturated during most of the year, but this state can rapidly change during periods of heavy rainfall. Therefore, [3] advocated monitoring variations in pore water pressures (both negative and positive) at specific sites during the year in order to assess their impact on slope stability. We use the calibrated geomorhologic model of [33] to generate plausible maps of the bedrock depth. The model was calibrated against a rich data set of distributed bedrock depth measurements using Bayesian inference with the DREAM algorithm [36,37]. Posterior maps of the simulated bedrock depth topography serve as input to a threedimensional finite-element (FE) water flow model of the bedrock-soil domain, and are used to evaluate hillslope stability for a 22-day rainfall record via numerical limit analysis [38] using the ensemble of simulated transient pore water pressures. Our analysis will also consider soil hydraulic parameter uncertainty derived from pedotransfer functions using the Rosetta program [39]. We are particularly interested in the coordinated impact of both sources of uncertainty (bedrock depth and soil hydraulic properties) on the mean SF and its associated 95\% confidence interval instead of looking at their marginal impact. The framework presented herein allows geotechnical engineers to address slope stability issues beyond those that can be addressed using deterministic methods, and provides a basis for reliability analyses of geotechnical hazards.

The remainder of this paper is organized as follows. Section 2 reviews the different building blocks of our integrated fluid flow and numerical limit analysis methodology. This framework is used herein to assess the SF values and corresponding failure probabilities. In Section 3 we are particularly concerned with quantification of soil hydraulic and bedrock depth uncertainties. This is followed in Section 4 with a detailed description of three different case studies of the same hillslope. Section 5 presents results of the three case studies, whereas Section 6 discusses the implications of our findings to hydrologic and geotechnical modeling. Finally, Section 7 concludes this manuscript with a summary of our main findings.

\section{Modeling framework}

We developed an integrated framework for stochastic slope stability analyses. The probabilistic framework couples a Monte Carlo algorithm with a three-dimensional variably-saturated flow model of the soil mantle and assesses hillslope stability via numerical limit analysis (NLA). The flow model solves numerically in threedimensions Richards' equation and simulates transient values of the pressure head, $\psi(\cdot)$, for the spatial coordinates, $x$ and $y$, and depth, $z$, of the hillslope and time, $t$, of the supplied rainfall data record. The values of $\psi(x, y, z, t)$ in the center of each tetrahedral element are used to characterize the soil-mantle's water pressures. These locations are indicated schematically with the red dot in the mesh of Fig. 1. The evolving pore water pressures then serve as input to NLA to solve numerically for the transient stress and velocity distributions of the soil-mantle, which in turn are used to calculate the SF during the rainfall record. The Monte Carlo algorithm is used to quantify the impact of uncertainty in the bedrock depth and the soil hydraulic properties on hillslope stability by repeated numerical solution of the NLA equations for the ensemble of pore water pressures simulated with the Richards-based flow model.

Our framework is coded in MATLAB and integrates the two numerical models so that users do not have to port data from one model to the next [10], thus simplifying considerably slope stability analyses. The MATLAB code has a built-in routine which generates automatically prismatic and tetrahedral $\mathrm{FE}$ meshes for the hillslope water flow model and NLA equations, respectively. The code furthermore has pre- and postprocessing capabilities to simplify model setup and visualization of the results. Fig. 1 provides a schematic overview of our coupled framework. Users have 


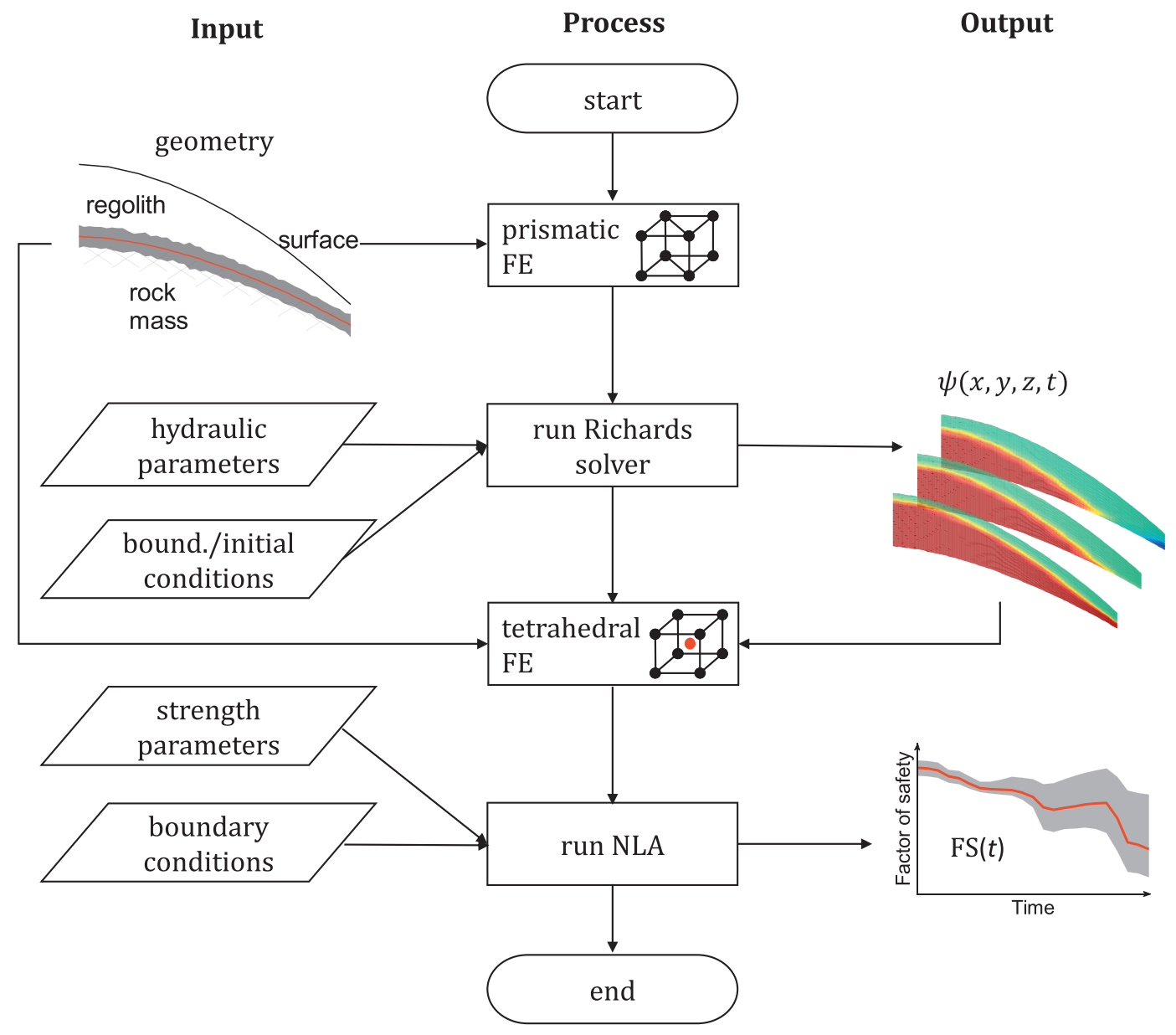

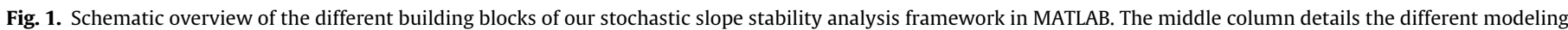

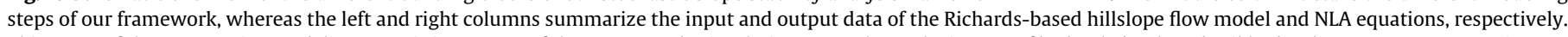

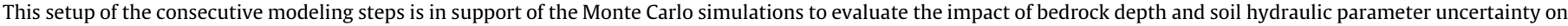
slope stability.

to supply several inputs to execute our framework, including slope geometry (this includes a detailed topographic map of the bedrock surface), initial and boundary conditions used by the hillslope water flow model and NLA, and the hydraulic and strength parameters of the domain of interest. Users can also change default settings of algorithmic variables used for mesh creation and refinement, as well as Monte Carlo simulations of the bedrock surface and soil hydraulic parameters. The framework also has built-in capabilities for distributed computing, which speeds up significantly stability analyses by evaluating the Monte Carlo realizations of the bedrock depth topography and soil-mantle's hydraulic properties on different processors.

The next subsections describe the different modeling steps of the flowchart presented in Fig. 1, and summarize the spatial discretizations and initial and boundary conditions that are used to solve numerically the governing equations of water flow and slope stability. Further details are presented in Appendices A and B. In Section 3 we then discuss our treatment of the bedrock topography and soil hydraulic properties and their associated uncertainty in support of probabilistic slope stability analyses.

\subsection{Variably saturated model description}

In this subsection we describe the Richards-based fluid flow model used to simulate the transient pore water pressures of the soil-mantled hillslope in Rio de Janeiro. The simulated pore water pressures serve as input to NLA to compute confidence intervals of the SF.

\subsubsection{Governing equation}

The hillslope water flow model solves the three-dimensional pressure head formulation of Richards' equation for the spatial coordinates, $x, y$ and $z(\mathrm{~L})$ of the soil-mantle given by

$$
\begin{aligned}
C(\psi) \frac{\partial \psi}{\partial t}+S_{s} S(\psi) \frac{\partial \psi}{\partial t}= & \frac{\partial}{\partial x}\left[K(\psi) \frac{\partial \psi}{\partial x}\right]+\frac{\partial}{\partial y}\left[K(\psi) \frac{\partial \psi}{\partial y}\right] \\
& +\frac{\partial}{\partial z}\left[K(\psi) \frac{\partial \psi}{\partial z}+1\right]
\end{aligned}
$$

where $\psi(\mathrm{L})$ is the pressure head, $C(\psi)\left(\mathrm{L}^{-1}\right)$ denotes the soil water capacity function, $S(\psi)(-)$ signifies the degree of saturation, $S_{\mathrm{s}}$ $\left(\mathrm{L}^{-1}\right)$ represents the specific storage, $K(\psi)(\mathrm{L} / \mathrm{T})$ is the HCF, and $t$ (T) denotes time. The degree of saturation is defined as

$S(\psi)=\frac{\theta(\psi)}{\theta_{\mathrm{s}}}$,

where $\theta(\psi)\left(\mathrm{L}^{3} / \mathrm{L}^{3}\right)$ is the moisture content, and $\theta_{\mathrm{s}}\left(\mathrm{L}^{3} / \mathrm{L}^{3}\right)$ denotes the saturated water content. Note that $S_{\mathrm{s}}$ can be omitted in our application since it does not affect the simulated moisture distribution and pore water pressures. 
Unfortunately, no analytic solutions exists of Eq. (1) for sloping soils with a complicated stratigraphy and realistic boundary conditions. We therefore resort to numerical solutions, and use a fully implicit finite-difference scheme with variable time steps to simulate spatially distributed values of the pressure head and moisture content. The quasi-Newton Broyden-Fletcher-Goldfarb-Shanno (BFGS) method $[40,41]$ was used to solve numerically in time Eq. (1) at relevant $x, y, z$ locations of the hillslope. This method calculates the Jacobian (derivative) matrix only once at each time, thereby reducing considerably the CPU cost for highly discretized FE meshes. The cited publications detail the numerical implementation of the BFGS method.

\subsubsection{Temporal and spatial discretization}

Numerical solutions of Eq. (1) require the users to define a suitable spatial and temporal discretization for the domain of interest. We use herein a mesh consisting of linear prismatic elements composed of six nodes. Fig. 2a presents a three-dimensional plot of the FE mesh of the experimental hillslope in Rio de Janeiro, which will be discussed in more detail later. Unfortunately, one cannot build the mesh without detailed knowledge of the surface and bedrock topography. The model domain was generated in our program by importing $x, y, z$ coordinates for the surface and bedrock topography. The MATLAB toolbox we developed herein allows users to define the density of the surface mesh (number of nodes/elements). The toolbox also allows users to define the number of nodes in the $z$ (vertical) direction between the hillslope surface and the bedrock. The structured mesh presented in Fig. 2a is made up of 9600 elements with 5797 nodal points. This mesh provides a good compromise between the CPU costs of the BFGS solver and the corresponding accuracy of the simulated distributed pressure head values. Indeed, as shown in Fig. 3, the use of a larger number of elements (and thus nodes) hardly changes the numerical results of our flow model. Since our measurements of the soil mantle did not reveal the presence of a well-defined stratigraphy with multiple layers [42], we conveniently assumed the hillslope interior to be homogeneous. Nonetheless, our MATLAB flow model can solve for water movement in heterogeneous soil-bedrock domains, if deemed appropriate.

The BFGS solver implements a variable time step, $\Delta t$, to solve numerically Eq. (1). This time step is reduced when convergence

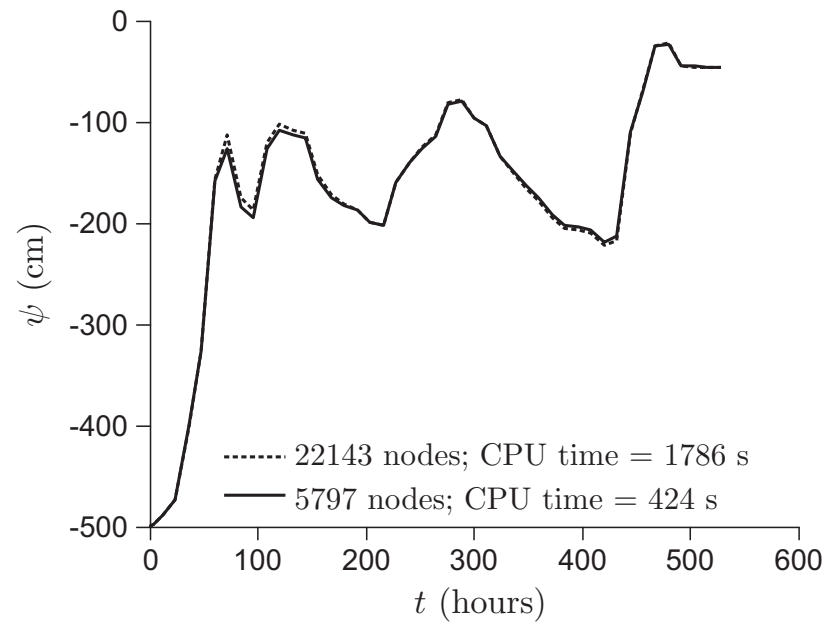

Fig. 3. Simulated pressure head values, $\psi(x, y, z, t)$, at some random node in the soilmantle of our hillslope using a mesh with 5797 nodal points (solid line) and a much more refined mesh composed of 22143 nodes (dashed line). The simulations appear almost identical, yet the CPU cost of the densest mesh was more than four times larger than its counterpart with 5797 nodes.

criteria of the simulated $\psi(x, y, z, t)$ values are not satisfied with the current value of $\Delta t$. Our flow model relates the increment of $\Delta t$ to the number of iterations used during the previous time step. The initial, minimum and maximum time steps were set to $0.01,10^{-9}$ and $1 \mathrm{~h}$, respectively. Based on the work of Paniconi et al. [43] we did set the convergence threshold of $\psi$ at $0.1 \mathrm{~m}$.

\subsubsection{Boundary and initial conditions}

Numerical solutions of Richards' equation were obtained by imposing a precipitation rate, $Q(\mathrm{~L} / \mathrm{T})$, across the surface boundary $(\Gamma)$ as follows

$q_{\mathrm{n}}=Q(t)$ at $\Gamma$,

where $q_{\mathrm{n}}$ represents the incoming flux, normal to the surface of the FE mesh. Rainfall was recorded at a station near the study site (Fig. 4). The measured hyetograph displayed three consecutive storm events (days 2-4, days 7-13 and days 18-21), which were

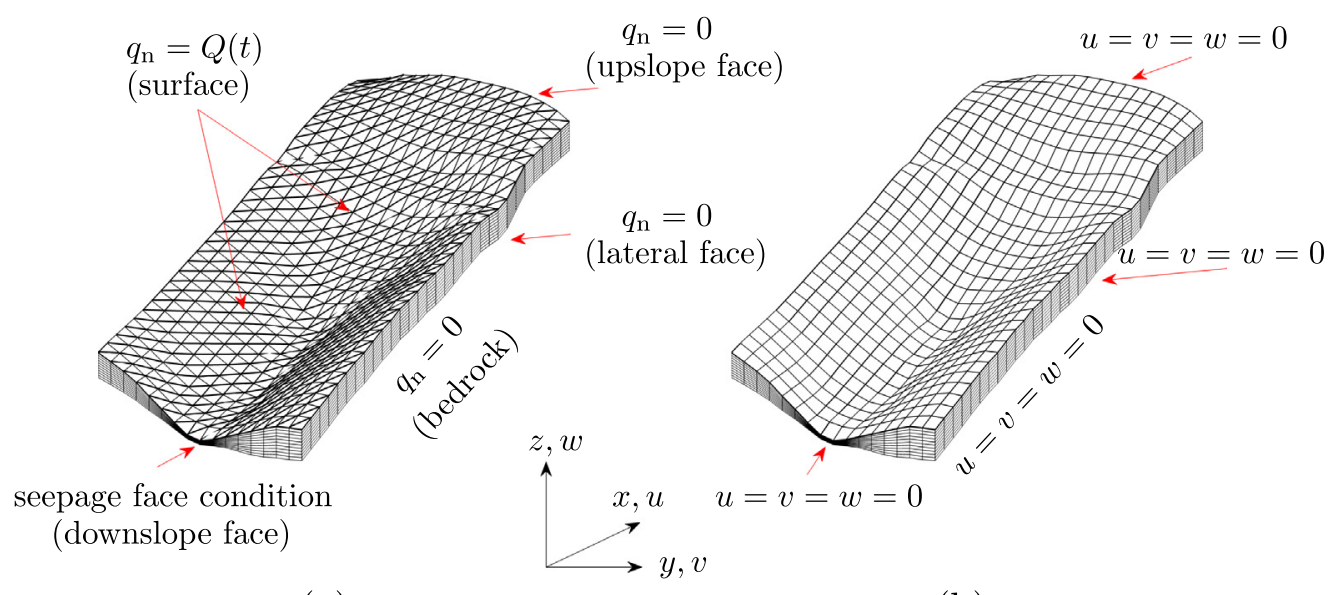

(a)

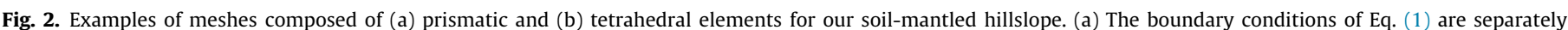

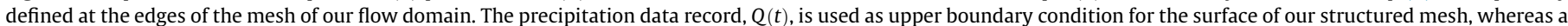

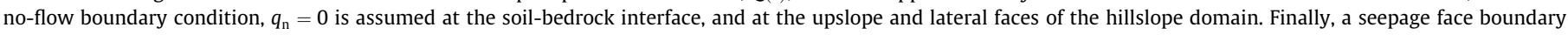

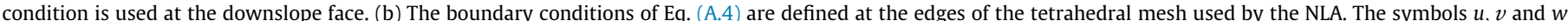

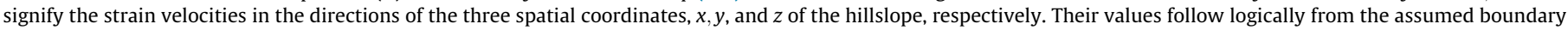
conditions, that is, a zero velocity equates to $u=v=w=0$. 


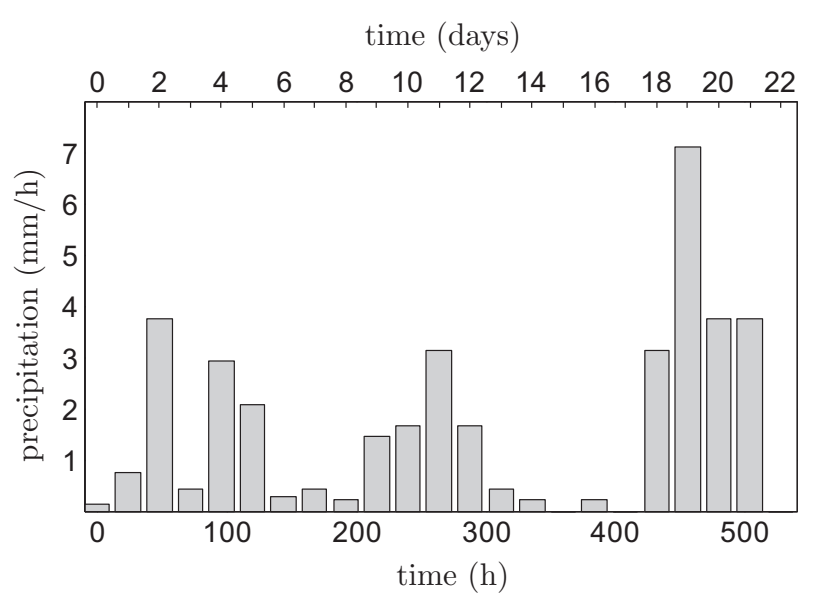

Fig. 4. Atmospheric boundary conditions used in all of our numerical simulations. The hyetograph envelopes a period of 22 days with hourly measurements of rainfall rates (mm/hour) from a nearby meteorological station.

separated well in time. The last of these three events exhibited the largest intensity and volume of rainfall. In this study, we assumed the infiltration flux at the surface nodes to be equivalent to measured rainfall rates. If, in response to this rainfall, the simulated pressure heads of the surface nodes became larger than zero, then the excess water was removed instantaneously by surface runoff and the pressure heads were set to zero [44]. If, at the end of some time step, $\Delta t$, the infiltration rate at some surface node was larger than the prescribed precipitation flux, then the infiltration flux was set equal to the measured hourly rainfall rate, $Q(t)$. We refer to Fig. 2a for definition of the boundary conditions of the hillslope. In summary, a seepage face boundary condition was assumed along the downslope face. The remaining boundary nodes of the soilbedrock interface and the lateral and upslope faces assumed a noflow boundary conditions, that is, $q_{\mathrm{n}}=0$.

In the absence of detailed information about the soil-mantle's pressure head values at the start of the 22-day experimental period, we preceded our simulations with a one-year spin-up period to derive reasonable initial values of $\psi(x, y, z, 0)$. We started the spin-up period with $\psi(x, y, z)=-500 \mathrm{~cm}$ and forced the flow model with a yearly record of measured daily rainfall rates from a nearby meteorological station in Rio de Janeiro (see Fig. 5). At the end of the 365-day spin-up period, the highest moisture contents (and thus pressure head values) were found at places of the slope with a relatively thin regolith depth. This simulated distribution of pressure head values was subsequently used as the initial

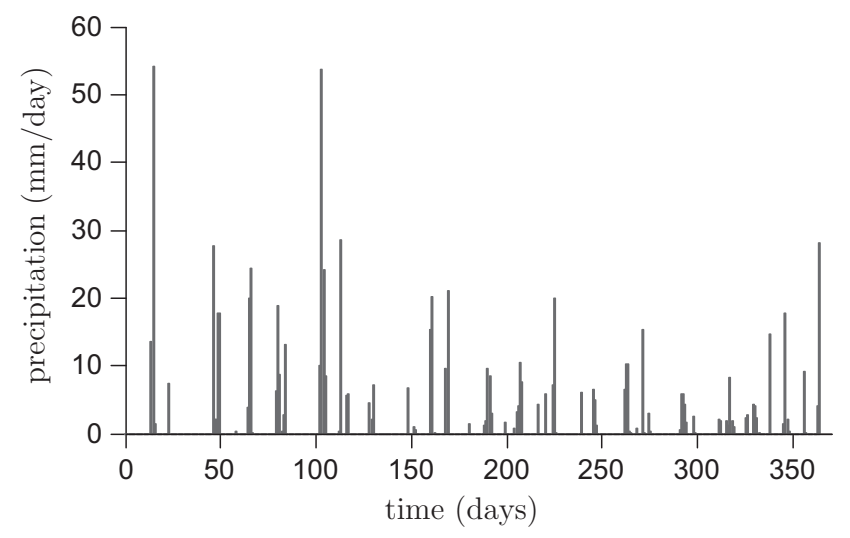

Fig. 5. Yearly record of daily precipitation rates used during the spin-up period. The data originated from a nearby meteorological station. soil-moisture state in the flow model to assess slope stability during the following 22-days. Of course, one can debate the choice of our spin-up period. We note that, despite recent research (e.g. see [45]), no consensus exists on what constitutes a proper spin-up time and period for particular applications. Without formal guidelines, our length of spin-up period is in agreement with [46]. It is important to stress here that the sensitivity of our flow model to the initial soil moisture state diminished rapidly during the 22day period because of the rather large intensity of the rainfall events of the hyetograph (see Fig. 4).

\subsubsection{Soil hydraulic properties}

Numerical solutions of Eq. (1) require knowledge of the hydraulic properties of the soil mantle. We use for this purpose the soil water characteristic curve (SWCC) and hydraulic conductivity function (HFC) of van Genuchten-Mualem (VGM) [47,48], which are given by

$S_{\mathrm{e}}(\psi)=\frac{\theta(\psi)-\theta_{\mathrm{r}}}{\theta_{\mathrm{s}}-\theta_{\mathrm{r}}}=\left\{\begin{array}{lll}\left(1+|\alpha \psi|^{n}\right)^{-m} & \text { for } \psi \leqslant 0 \\ 1 & \text { for } \psi>0\end{array}\right.$

$K(\psi)=K_{\mathrm{s}} S_{\mathrm{e}}(\psi)^{L}\left\{1-\left[1-S_{\mathrm{e}}(\psi)^{1 / m}\right]^{m}\right\}^{2}$

where $S_{\mathrm{e}}(-)$ is effective saturation, $\theta_{\mathrm{r}}\left(\mathrm{L}^{3} / \mathrm{L}^{3}\right)$ denotes the residual water content, $\alpha\left(\mathrm{L}^{-1}\right)$ is a proxy of the reciprocal of the air-entry value of the soil, $n$ and $m$ are unitless shape parameters of the SWCC and $\mathrm{HCF}, K_{\mathrm{s}}(\mathrm{L} / \mathrm{T})$ denotes the saturated hydraulic conductivity and $L$ $(-)$ is a pore-connectivity parameter. We make the common assumptions that $m=1-1 / n$ and $L=0.5$, and use the remaining parameters, $\left\{\theta_{\mathrm{s}}, \theta_{\mathrm{r}}, \alpha, n, K_{\mathrm{s}}\right\}$, to characterize the hydraulic properties of the soil mantle.

\subsection{Numerical limit analysis}

Numerical limit analysis (NLA) was used to evaluate the geotechnical stability of the hillslope under variably-saturated conditions. NLA as implemented in our study uses as input the pore water pressures simulated by the Richards-based flow model (see Fig. 1) and returns the corresponding estimates of the collapse load, that is, the maximum load that can be sustained by the hillslope. We briefly summarize the main elements of NLA, and refer readers to the excellent review by Sloan [49] for further details on limit analysis approaches.

We use the mixed-formulation, second-order cone programming implementation of [38] to solve for the stress and velocity distributions in the three-dimensional finite element mesh of our hillslope. The mixed-formulation assumes stresses to be constant within each $\mathrm{FE}$, while velocities in the $u, v$ and $w$ directions are varied linearly between neighboring nodes [50]. The second-order cone programming [51] exploits the underlying convexity of the optimization problem and searches for the collapse factor that satisfies the equivalent static and kinematic principles of limit analysis [52].

A summarizes the NLA method described by Camargo et al. [38] and adopted herein for computation of the SF of the hillslope during the 22-day rainfall record.

\section{Treatment of bedrock depth and soil hydraulic uncertainty}

This section characterizes the bedrock depth topography and the hydraulic functions of the soil mantle. We are particularly concerned with proper treatment of their uncertainty. 


\subsection{Uncertainty of bedrock topography}

In a recent paper, Gomes et al. [33] developed a geomorphologic model to predict the spatial distribution of depth to bedrock (DTB) from high-resolution topographic data, numerical modeling and Bayesian analysis. We used the DTB model of [33] and refer interested readers to this publication for further details. Bayesian analysis was used to reconcile the DTB model with distributed bedrock depth measurements. We used Markov chain Monte Carlo simulation (MCMC) with the DREAM algorithm [36,37] for posterior inference in the Bayesian framework. This approach searched the DTB model parameter space for posterior solutions that "best" honor the observed bedrock depth data. The posterior mean bedrock topography simulated with the DTB model was shown to be in good quantitative agreement with point observations of the regolith depth. The associated prediction intervals appeared rather large, yet enveloped the vast majority of bedrock depth observations. Note that [8] used the DREAM algorithm to evaluate slope stability under unsaturated conditions. We refer to this publication for a geotechnical application of Bayesian analysis. B summarizes how we derived the posterior mean bedrock topography and a sample set of surfaces that quantify its associated $95 \%$ prediction intervals.

DTB measurements were carried out in two adjacent watersheds in the Papagaio river basin, Rio de Janeiro, Brazil. The two watersheds studied extensively by several authors in the literature after mass movements occurred in 1996 (see for instance [53]). The geographic location of the field site is depicted with a red cross in Fig. 6, which also displays (right hand side) the topography of the two experimental basins. The white dots indicate the measurement locations of the bedrock depth using a light dynamic cone penetrometer. The eight black circles represent locations where additional soil samples were collected via drilling with a mechanical auger. We refer to [42] for a detailed description of the field campaign and measurements.

We next illustrate the results obtained with the DTB model, and display in Fig. 7 the main morphological features of the experimental hillslope. The top panel presents a three-dimensional view of the surface elevation of the hillslope as derived from highresolution topographic data. The elevation of the hillslope ranges between 280 and $340 \mathrm{~m}$ above mean sea level, with slopes that are steepest near the crest (hilltop) and become increasingly planar downslope towards the drainage valley. The color map that is projected onto the surface topography depicts the posterior mean depth to (unweathered) bedrock simulated with the DTB model. The DTB model produced a rather smooth bedrock surface from the hilltop to the drainage channel in the valley. The bottom panel of Fig. 7 presents a two-dimensional cross section of the hillslope and depicts the topography of the surface (solid black line) and DTB simulated posterior mean bedrock surface (solid red line) of

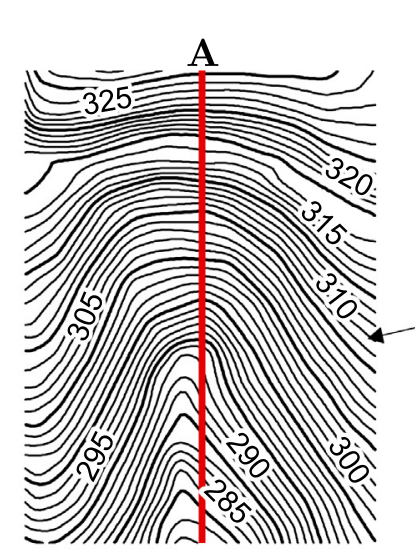

$\mathbf{A}^{\prime}$

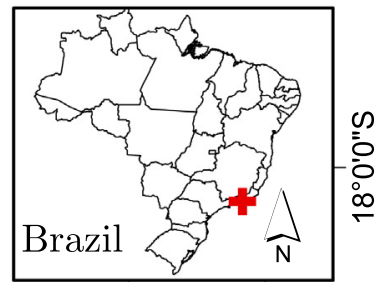

$60^{\circ} 0^{\prime} \mathrm{O}^{\prime \prime} \mathrm{W} 40^{\circ} \mathrm{O}^{\prime} \mathrm{O} \mathrm{W} \mathrm{W}$
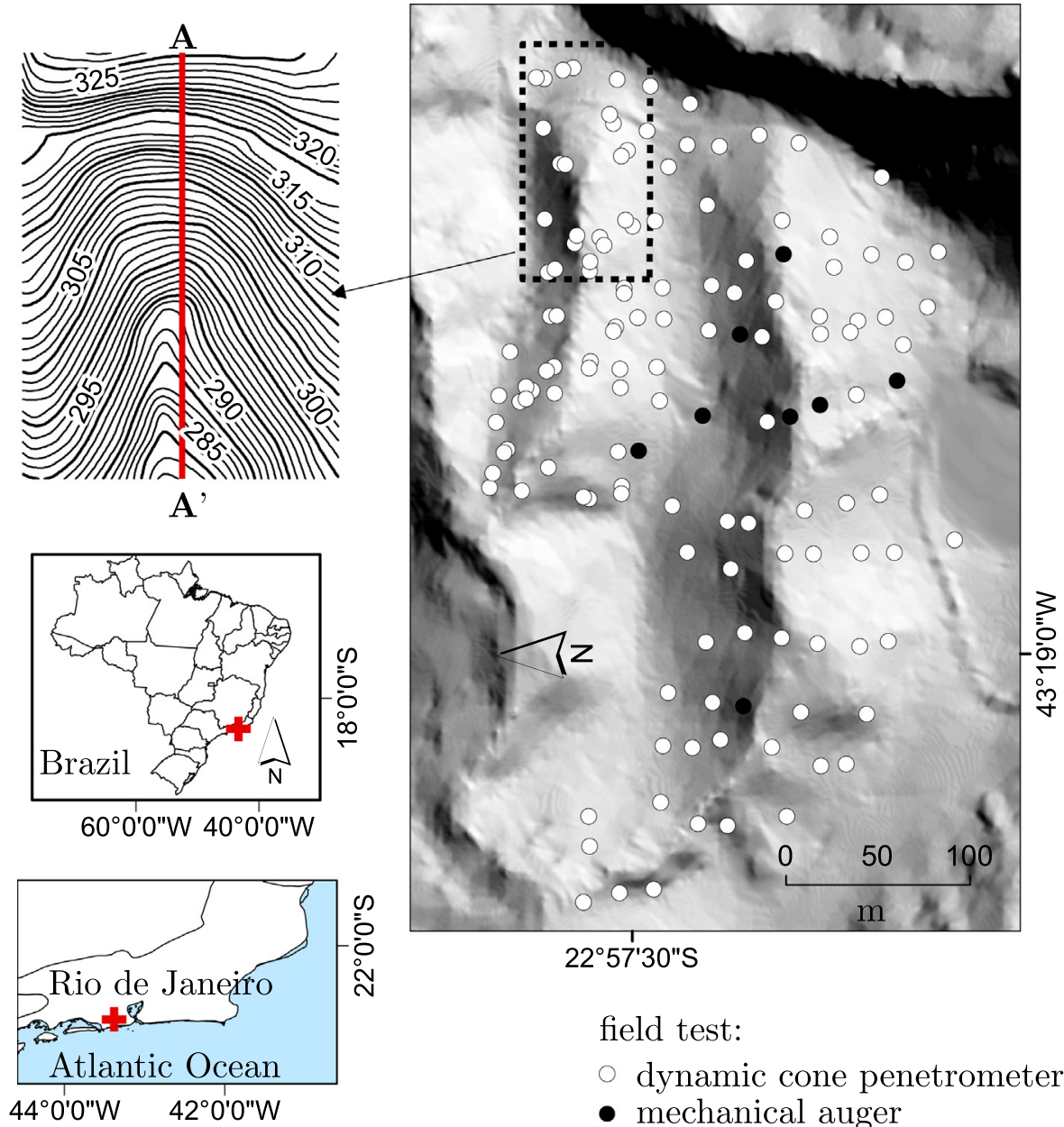

field test:

- dynamic cone penetrometer

- mechanical auger

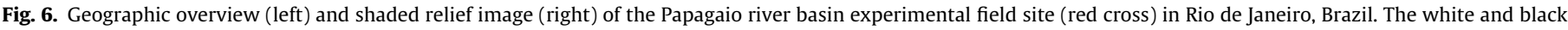

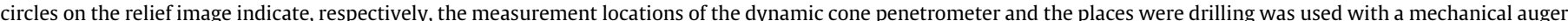

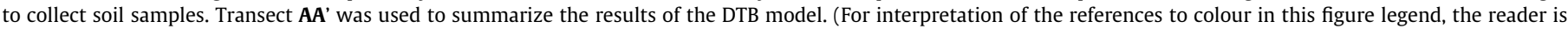
referred to the web version of this article.) 

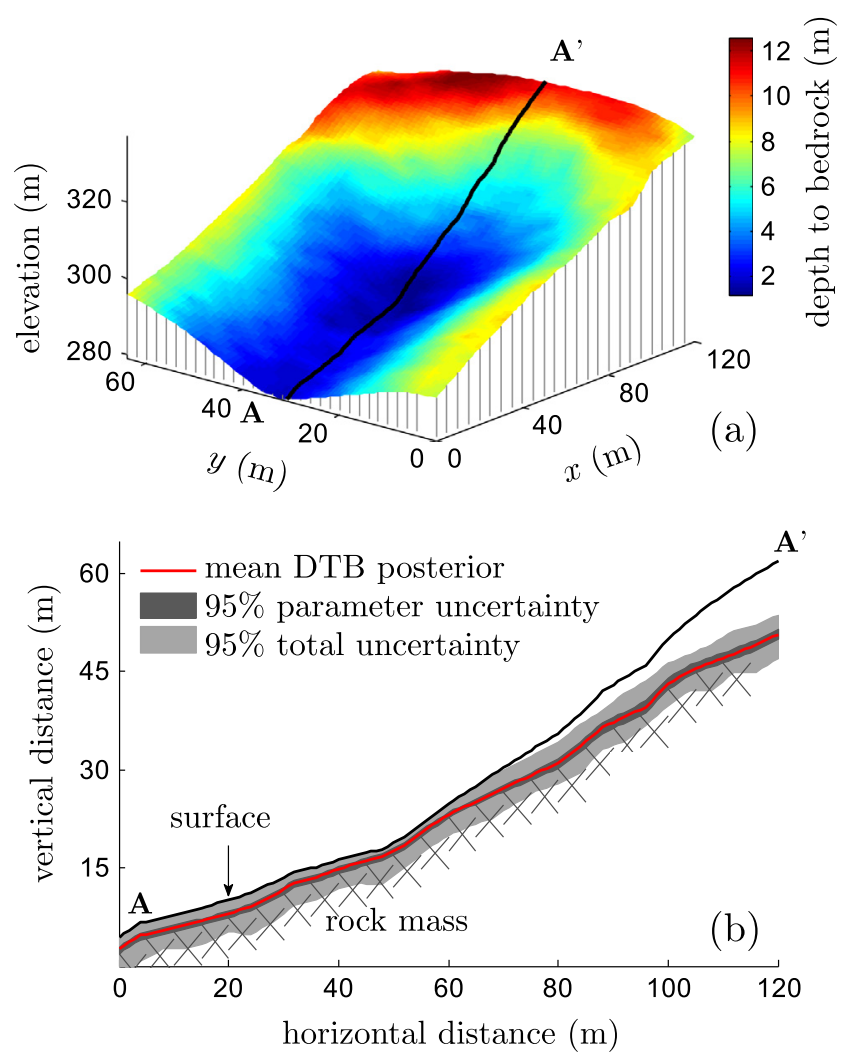

Fig. 7. Topography and bedrock surface of the hillslope under investigation. (a) Color projection of the posterior mean bedrock depth simulated with the DTB model. The vertical bars along the axes denote the elevation of the hillslope. (b) Two-dimensional plot of the surface topography (solid black line) and posterior mean bedrock surface (solid red line) of transect $\mathbf{A A}$ '. The elevations refer to the base of the hillslope (drainage valley). The dark and light gray regions denote the $95 \%$ prediction uncertainty intervals of the DTB model due to parameter uncertainty and total uncertainty. (For interpretation of the references to colour in this figure legend, the reader is referred to the web version of this article.)

transect $\mathbf{A} \mathbf{A}^{\prime}$. The dark gray region in this graph represents the $95 \%$ prediction intervals of the DTB model due to parameter uncertainty. This uncertainty was derived from the $M$ posterior realizations stored in the three-dimensional array $\hbar$, as detailed in Appendix B.

Note that in Fig. 7 we also portrayed the 95\% ranges of the total DTB model uncertainty (gray region). These enlarged prediction intervals of the bedrock depth summarize the combined impact of DTB parameter and model uncertainty, respectively, and are computed by adding to the simulated bedrock depths of each posterior realization of $\hbar$ a random draw from the model error distribution. This step introduces irregularities in the soil-bedrock interface and characterizes structural inadequacies (epistemic errors) of the DTB model. We made herein the common assumption of a zeromean normally distributed model error with standard deviation equal to the root mean square error of the posterior mean DTB model fit. The resulting "perturbed" ensemble of $M$ different bedrock depth maps summarizes the uncertainty in the bedrock topography underneath the hillslope and is now used in our Monte Carlo framework for probabilistic slope stability analysis.

Table 1 lists summary statistics of the gradient of the (measured) hillslope topography (middle column) and the DTB simulated posterior mean bedrock surface (right column). Note that the surface topography exhibited the largest gradients with mean and minimum values that are larger than their counterparts of the bedrock surface. The maximum gradients of the hillslope surface and soil-bedrock topography were very similar $\left(43-44^{\circ}\right)$.
Table 1

Comparison of the mean (top row), maximum (middle row) and minimum (bottom row) gradients of the surface topography (middle column) and posterior mean soilbedrock interface simulated with the DTB model (right column).

\begin{tabular}{lll}
\hline Attribute & Surface & Bedrock \\
\hline Mean gradient $\left(^{\circ}\right)$ & 30 & 23 \\
Max. gradient $\left(^{\circ}\right)$ & 44 & 43 \\
Min. gradient $\left({ }^{\circ}\right)$ & 9 & 3 \\
\hline
\end{tabular}

\subsection{Uncertainty in the soil hydraulic properties}

Now that the soil-bedrock interface has been delineated, we are left with characterization of the hydraulic properties of the soil mantle. In the absence of soil water retention and unsaturated hydraulic conductivity data, we used the Rosetta program of [39] to estimate values of the VGM parameters in the soil hydraulic functions given by Eqs. (4) and (5). Rosetta uses a set of hierarchical pedotransfer functions to estimate the VGM parameters from basic soil data, such as soil textural class, sand, silt, and clay percentages, bulk density, and direct water retention observations. We followed the methodology developed by [22] and quantified the uncertainty in the hydraulic properties (SWCC and HCF) of the soil mantle as follows.

First, 52 measurements of soil texture (sand, silt and clay \%) at eight different locations and depths (see black circles in Fig. 6) were used to compute the mean texture, a, of the soil mantle and its associated $3 \times 3$ covariance matrix, b. We drew randomly a large sample of $P$ texture samples from $\mathcal{N}_{3}(\mathbf{a}, \mathbf{b})$, a three-variate normal distribution with mean $\mathbf{a}$ and covariance matrix $\mathbf{b}$, and evaluated each of the $P$ samples using Rosetta. This did result in a large ensemble of $P$ realizations of the VGM soil hydraulic parameters, $\left\{\theta_{\mathrm{s}}, \theta_{\mathrm{r}}, \alpha, n, K_{\mathrm{s}}\right\}$. Table 2 summarizes the results of our Rosetta ensemble, including mean values of the soil hydraulic parameters (third column), their standard deviations (fourth column), and linear correlation coefficients (last five columns). The negative correlation coefficient $(-0.86)$ between $\log _{10}(\alpha)$ and $\log _{10}(n)$ is in agreement with field data and supported by statistical analysis of these two soil hydraulic parameters [54,18]. Indeed, Phoon et al. [18] argued that this correlation between $\alpha$ and $n$ should be honored otherwise this might lead to a SWCC that does not characterize accurately the retention function of the soil domain under investigation. A similar conclusion was reported independently by Scharnagl et al. [22] who showed that a proper treatment of the correlation structure between the soil hydraulic parameters is a prerequisite to accurate sampling of the water retention functions. The relatively low correlation between the VGM parameter pairs $\theta_{\mathrm{r}}-\theta_{\mathrm{s}}$ and $\log _{10}(\alpha)-\log _{10}\left(K_{\mathrm{s}}\right)$ is in agreement with previous findings (e.g., [22]).

The $P$ different ROSETTA predictions of the VGM parameters were used next to characterize the uncertainty in the hydraulic properties of the soil-mantle. Alternatively, one could generate $P$ realizations of the VGM parameters by drawing randomly from a five-variate normal distribution with mean and covariance matrix from the $P$ Rosetta realizations. We illustrate the results of this second approach in Fig. 8, which shows the mean (red line) and 95\% confidence intervals (gray region) of the water retention (top) and hydraulic conductivity (bottom) functions. The two functions suggest an excellent water holding capacity of the soil mantle, with pressure heads that must be below $-80 \mathrm{~cm}$ for air to enter the pores. This finding is consistent with our soil textural data, which demonstrate relatively high percentages of silt and clay [42]. The confidence interval of the SWCC is almost perfectly symmetrical, being similarly large at saturation and the residual moisture content, and smallest in the interval between the two inflection points (moisture contents between 0.2 and $0.4 \mathrm{~cm}^{3} / \mathrm{cm}^{3}$ ). Note that the 
Table 2

Mean values, standard deviations and correlation coefficients of the Rosetta [39] predicted soil hydraulic parameters.

\begin{tabular}{|c|c|c|c|c|c|c|c|c|}
\hline \multirow[t]{2}{*}{ Parameter } & \multirow[t]{2}{*}{ Unit } & \multirow[t]{2}{*}{ Mean } & \multirow[t]{2}{*}{ Standard deviation } & \multicolumn{5}{|c|}{ Correlation coefficients } \\
\hline & & & & $\theta_{\mathrm{r}}$ & $\theta_{\mathrm{s}}$ & $\log _{10}(\alpha)$ & $\log _{10}(n)$ & $\log _{10}\left(K_{\mathrm{s}}\right)$ \\
\hline$\theta_{\mathrm{r}}$ & $\mathrm{cm}^{3} \mathrm{~cm}^{-3}$ & 0.0577 & 0.0153 & 1.00 & & & & \\
\hline$\theta_{\mathrm{s}}$ & $\mathrm{cm}^{3} \mathrm{~cm}^{-3}$ & 0.4337 & 0.0159 & 0.09 & 1.00 & & & \\
\hline $\log _{10}(\alpha)$ & $\mathrm{cm}^{-1}$ & -2.2719 & 0.0748 & 0.15 & 0.24 & 1.00 & & \\
\hline $\log _{10}(n)$ & - & 0.2146 & 0.0140 & -0.58 & -0.04 & -0.86 & 1.00 & \\
\hline $\log _{10}\left(K_{\mathrm{s}}\right)$ & $\mathrm{cm} / \mathrm{h}$ & 0.0583 & 0.0128 & -0.97 & 0.12 & -0.10 & 0.57 & 1.00 \\
\hline
\end{tabular}

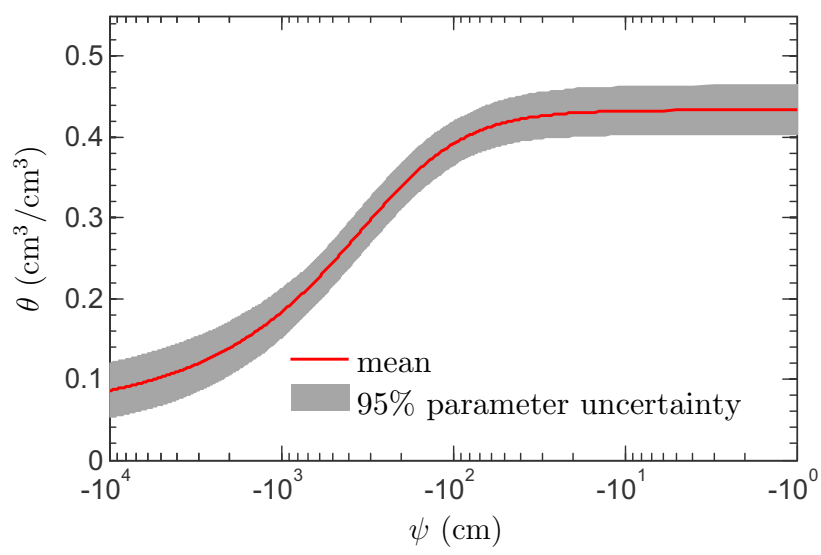

(a)

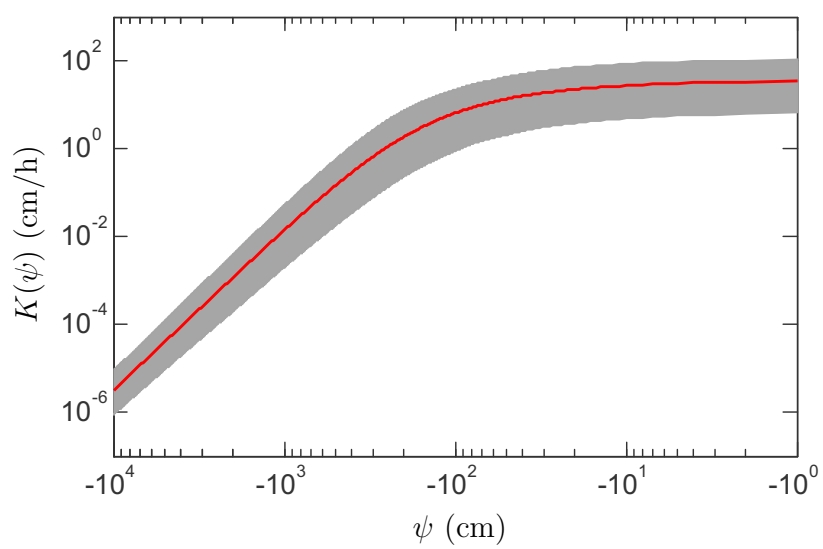

(b)

Fig. 8. 95\% prediction intervals of the hydraulic functions of the soil mantle derived with Rosetta using 52 different soil textural samples from eight different measurement locations on the hillslope in Rio de Janeiro, Brazil: (a) water retention function, and (b) unsaturated hydraulic conductivity function. The hydraulic functions of the mean VGM parameters are separately indicated with solid red lines. (For interpretation of the references to colour in this figure legend, the reader is referred to the web version of this article.)

confidence interval at $\psi=0 \mathrm{~cm}$ is determined only by the value of $\theta_{\mathrm{s}}$, whereas the ranges at $\psi=-10^{4} \mathrm{~cm}$ are determined by the values of $\theta_{r}$ and $n$. The HCF exhibits asymmetrical confidence intervals that become increasingly smaller (even on a logarithmic scale) with decreasing pressure heads as the soil dries out. Uncertainty in the HCF is determined mostly by $K_{s}$.

\subsection{Strength parameters}

Numerical simulations with the flow model and NLA also require estimates of the strength parameters, $c^{\prime}, \phi^{\prime}$ and $\phi_{\mathrm{b}}$ in Eq. (A.1). Additionally, values of the specific weights of natural soil, $\gamma_{\text {nat }}$, saturated soil, $\gamma_{\text {sat }}$, and water, $\gamma_{w}$, are required for computation
Table 3

Constant values of the geotechnical parameters used in our numerical simulations.

\begin{tabular}{llll}
\hline Type & Parameter & Value & Unit \\
\hline Soil and water & $\gamma_{\mathrm{w}}$ & 10 & $\mathrm{kN} / \mathrm{m}^{3}$ \\
Properties & $\gamma_{\text {nat }}$ & 18 & $\mathrm{kN} / \mathrm{m}^{3}$ \\
& $\gamma_{\text {sat }}$ & 20 & $\mathrm{kN} / \mathrm{m}^{3}$ \\
Strength & $c^{\prime}$ & 5 & $\mathrm{kPa}$ \\
Parameters & $\phi^{\prime}$ & 30 & $\circ$ \\
& $\phi_{\mathrm{b}}$ & 15 & $\circ$ \\
\hline
\end{tabular}

of the stress field, $\boldsymbol{\sigma}$ in Eq. (A.3). Table 3 lists the values of the specific weights and strength parameters used herein. We conveniently assumed constant values of the strength parameters in all of our numerical simulations. This approach ignores spatial variabilities in $c^{\prime}$ and $\phi^{\prime}$ [11], and may lead to inadequate characterization of the stability of hillslopes during rainfall events $[8,14]$. Nevertheless, the use of constant strength parameters simplifies investigations into the impact of bedrock depth uncertainty and/or soil hydraulic uncertainty in slope stability studies.

\section{Case studies}

The MATLAB framework with its various elements and settings pertained to the variably-saturated flow model and NLA was used next to assess the impact of uncertainty in the bedrock depth and hydraulic parameters on the stability of the soil-mantled hillslope in Rio de Janeiro. A topographic map of the hillslope was shown previously in Fig. 7, including a three-dimensional color projection of the underlying bedrock surface. We also presented in Fig. 2 two example FE meshes of the hillslope that will be used by the water flow model and NLA. We describe below three different case studies to illustrate our findings. The first two case studies examine only the marginal (individual) impact of bedrock depth uncertainty (case study 1) and soil hydraulic parameter uncertainty (case study 2 ) on slope stability. The third case study evaluates their joint or combined impact on hillslope stability.

\subsection{Case study 1: Uncertainty in bedrock topography}

This first case study considered the impact of bedrock topographic uncertainty on slope stability. We necessarily assumed mean values of the hydraulic parameters of the soil mantle (see Table 2). A total of 100 different bedrock depth maps were drawn at random from the "perturbed" ensemble of posterior DTB-model simulations. This number of realizations was deemed sufficient to characterize the uncertainty in the bedrock topography underneath the hillslope (see Fig. B.1). The MATLAB framework created automatically, for each bedrock depth map, two FE meshes: one composed of prismatic elements and one comprising tetrahedral elements.

To provide a better understanding of the variations in the bedrock topography of the Monte Carlo ensemble, consider Fig. 9 which displays graphically the regolith surface of two plausible 


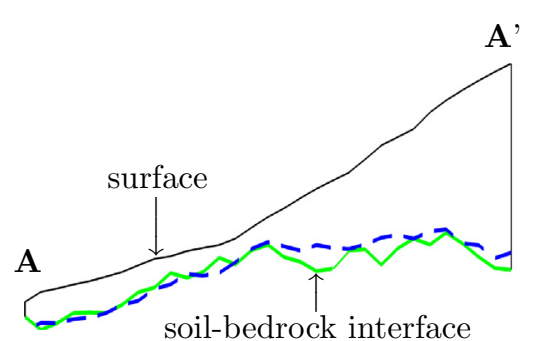

(a)

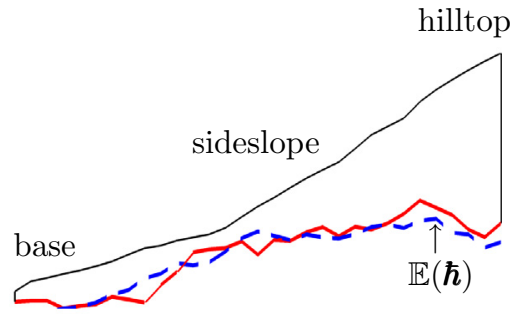

(b)

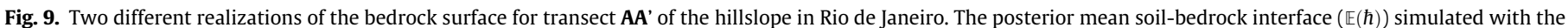

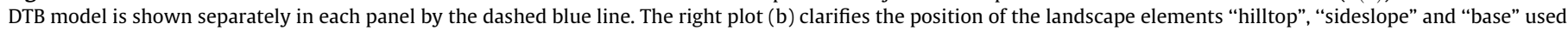
herein to discuss our findings. (For interpretation of the references to colour in this figure legend, the reader is referred to the web version of this article.)

realizations, coined $\mathbf{H}_{1}$ and $\mathbf{H}_{2}$. The two samples are characterized with the transect $\mathbf{A} \mathbf{A}^{\prime}$ depicted previously in Fig. 7. The posterior mean bedrock surface simulated with the DTB model is indicated separately in each plot using the dashed blue line. We used green (a) and red (b) colors to differentiate between the bedrock topographies of $\mathbf{H}_{1}$ and $\mathbf{H}_{2}$. The shape of the two surfaces in Fig. 9 will enhance our understanding of the simulated flow patterns and failure mechanisms. Note that the two bedrock surfaces exhibit many of the common features found in Rio de Janeiro [3]. To simplify interpretation we will use the landscape elements "hilltop", "sideslope" and "base" to discuss our findings. Their position is indicated in Fig. 9b.

The 100 prismatic FE meshes served as input to the soil water flow model to create an ensemble of transient pressure head values of the hillslope interior during the 22-day experimental period. The 100 transient simulations generated input to the tetrahedral FE meshes of the NLA to evaluate slope stability.

\subsection{Case study 2: Uncertainty in the soil hydraulic parameters}

In this study case, the uncertainty in the VGM parameters was evaluated by defining a prior distribution of the soil hydraulic parameters. This informative prior distribution can significantly reduce the uncertainty of the soil hydraulic parameters in back analyses [8] and avoid unrealistic water retention and hydraulic conductivity functions [18]. A total of 100 samples of the soil hydraulic parameters were generated by drawing from a multivariate normal distribution $\mathcal{N}\left(\boldsymbol{\mu}_{\mathrm{p}}, \boldsymbol{\Sigma}_{\mathrm{p}}\right)$ with mean $\boldsymbol{\mu}_{\mathrm{p}}$ and covariance matrix, $\boldsymbol{\Sigma}_{\mathrm{p}}$ (Section 3.2). We ignore uncertainty in the bedrock depth and assume the posterior mean bedrock topography, $\mathbb{E}(\hbar)$, as illustrated previously in Fig. 9.
Utilizing the same method as adopted in the previous subsection, two samples of soil hydraulic parameters were drawn from $\mathcal{N}\left(\boldsymbol{\mu}_{\mathrm{p}}, \boldsymbol{\Sigma}_{\mathrm{p}}\right)$ to help us better understand the effects of the SWCC and HCF on the Monte Carlo results. The two samples are referred to hereafter as $\mathbf{p}_{1}$ and $\mathbf{p}_{2}$, respectively, and assume different values of the soil hydraulic parameters $\mathbf{p}=\left\{\theta_{\mathrm{s}}, \theta_{\mathrm{r}}, \alpha, n, K_{\mathrm{s}}\right\}$, as listed in Table 4. For completeness, the last row of Table 4 lists the mean values of the soil hydraulic parameters, $\boldsymbol{\mu}_{\mathrm{p}}$. The saturated conductivity of $\mathbf{p}_{1}\left(K_{\mathrm{s}}=4.32 \mathrm{~cm} / \mathrm{h}\right)$ was found to be higher than the sample mean $\left(K_{\mathrm{s}}=1.15 \mathrm{~cm} / \mathrm{h}\right)$. The opposite is true for $\mathbf{p}_{2}$ which exhibited a much lower saturated conductivity $\left(K_{\mathrm{s}}=0.76 \mathrm{~cm} / \mathrm{h}\right)$.

\subsection{Case study 3: Combined uncertainty in bedrock depth and soil hydraulic functions}

Case study 3 treats the combined effect of uncertainty in the bedrock surface and the soil hydraulic parameters. The $M$ realizations of the bedrock topography now have different hydraulic parameter values of the soil mantle by drawing from the multivariate normal prior distribution of the VGM parameters (Section 4.2). Specifically, we illustrate our findings with the help of two bedrock-soil hydraulic parameter samples, coined $\mathbf{S}_{13}$ and $\mathbf{S}_{23}$. These two samples use the bedrock surfaces, $\mathbf{H}_{1}$ and $\mathbf{H}_{2}$ of Fig. 9 and the hydraulic parameter values, $\mathbf{p}_{1}$ and $\mathbf{p}_{2}$ of Table 4 , i.e., $\mathbf{S}_{13}=\left\{\mathbf{H}_{1} ; \mathbf{p}_{1}\right\}$ and $\mathbf{S}_{23}=\left\{\mathbf{H}_{2} ; \mathbf{p}_{2}\right\}$, where the subscripts of $\mathbf{S}_{13}$ refer to sample 1 of the case study 3 , etc.

Table 5 summarizes the three case studies used to evaluate slope stability in the presence of bedrock depth and soil hydraulic parameter uncertainty. The table also lists several samples used to clarify our findings. Results are discussed in the next section.

Table 4

Values of the VGM soil hydraulic parameters used in case study $1\left(\boldsymbol{\mu}_{\mathrm{p}}\right)$, and their values of samples $\mathbf{p}_{1}$ and $\mathbf{p}_{2}$, used in case studies 2 and 3.

\begin{tabular}{|c|c|c|c|c|c|}
\hline Sample & $\theta_{\mathrm{s}}\left(\mathrm{cm}^{3} \mathrm{~cm}^{-3}\right)$ & $\theta_{\mathrm{r}}\left(\mathrm{cm}^{3} \mathrm{~cm}^{-3}\right)$ & $\alpha\left(\mathrm{cm}^{-1}\right)$ & $n(-)$ & $K_{\mathrm{s}}(\mathrm{cm} / \mathrm{h})$ \\
\hline $\mathbf{p}_{1}$ & 0.453 & 0.036 & 0.0056 & 1.66 & 4.32 \\
\hline $\mathbf{p}_{2}$ & 0.425 & 0.063 & 0.0042 & 1.68 & 0.76 \\
\hline$\mu_{\mathrm{p}}$ & 0.429 & 0.056 & 0.0055 & 1.63 & 1.15 \\
\hline
\end{tabular}

Table 5

Summary of the three case studies and their samples used to illustrate our findings.

\begin{tabular}{|c|c|c|c|c|}
\hline \multirow[t]{2}{*}{ Case } & \multicolumn{2}{|c|}{ Source of uncertainty } & \multicolumn{2}{|c|}{ Samples } \\
\hline & Bedrock surface & Hydraulic parameters & 1 & 2 \\
\hline 1 & $\hbar$ & $\mu_{\mathrm{p}}$ & $\mathbf{S}_{11}=\left\{\mathbf{H}_{1} ; \mu_{\mathrm{p}}\right\}$ & $\mathbf{S}_{21}=\left\{\mathbf{H}_{2} ; \mu_{\mathrm{p}}\right\}$ \\
\hline 2 & $\mathbb{E}(\hbar)$ & $\mathcal{N}\left(\boldsymbol{\mu}_{\mathrm{p}}, \boldsymbol{\Sigma}_{\mathrm{p}}\right)$ & $\mathbf{S}_{12}=\left\{\mathbb{E}(\hbar) ; \mathbf{p}_{1}\right\}$ & $\mathbf{S}_{22}=\left\{\mathbb{E}(\hbar) ; \mathbf{p}_{2}\right\}$ \\
\hline 3 & $h$ & $\mathcal{N}\left(\boldsymbol{\mu}_{\mathrm{p}}, \boldsymbol{\Sigma}_{\mathrm{p}}\right)$ & $\mathbf{S}_{13}=\left\{\mathbf{H}_{1} ; \mathbf{p}_{1}\right\}$ & $\mathbf{S}_{23}=\left\{\mathbf{H}_{2} ; \mathbf{p}_{2}\right\}$ \\
\hline
\end{tabular}




\section{Results}

\subsection{Uncertainty in the safety factor}

Fig. 10 shows the evolution of the mean SF (solid red line) and its associated $95 \%$ confidence intervals (gray region) for case study 1 (a), case study 2 (b) and case study 3 (c). To better interpret the results, we also plotted separately in the figure the measured hyetograph and listed the precipitation amounts on the left $y$-axis.

Fig. 10a shows that the first storm between $t=0$ and $t=8$ (days) decreased the mean SF steadily from values of 1.70 to about 1.60 , in response to increased storage of water in the soil mantle. The associated 95\% intervals of the SF indicated a small control of the bedrock topography on slope stability during the first storm event. The second storm event between days 9 and 13 exerted far more control on slope stability. The SF plummeted after the peak rainfall on day 11 from 1.60 to about 1.25 on day 13 . The second storm event also increased substantially the width of the $95 \%$ intervals of the SF. During the next four consecutive dry days (days 14-17), the stability of the hillslope improved somewhat with a mean SF on day 17 of about 1.35, while the associated 95\% ranges that exhibited a smaller spread. The third and last storm event (days 18 to 22) was most severe, with its relatively large precipitation amount threatening the stability of the hillslope. Indeed, the mean SF of the hillslope deteriorated rapidly from values of about 1.35 on day 18 to 0.95 at the end of the 22-day simulation period.
The hillslope had become unstable and prone to mass movement and failure during the last few days of this third storm event. The 95\% intervals of the SF became relatively low, yet exhibited a much larger spread on day 18 (1.2-1.4) than on day 22 (0.9-1.0). Thus, the bedrock topography exerted far more control on the slope stability on day 18 than on day 22 .

We next analyzed how uncertainty in the soil hydraulic parameters affected the simulated SF values (Fig. 10b). The mean SF, represented by the red line, was very similar to the values obtained for case study 1 (Fig. 10a). However, during the first storm event between 0 and 5 days, the 95\% confidence intervals exhibit very tight bounds, thus suggesting no control of the soil hydraulic parameters on slope stability. We will revisit this assumption later. Fig. 10b shows that, after some precipitation threshold is reached, the $95 \%$ intervals of the SF increase. This occurs after about $t=5$ days. Between the second and third precipitation events, the bounds reached their maximum spread. By comparison, Fig. 10a and b show that, a priori, the effects of both sources of uncertainty (bedrock depth and soil hydraulic parameters) are quite similar.

Fig. 10c presents plots of the mean SF and its uncertainty bounds for case study 3 . While the mean values are very similar as those of the other two case studies, the 95\% confidence intervals are now slightly greater. The uncertainty during the first rainfall event (until $t=5$ days) seems related more to the variability in bedrock depth, rather than the soil hydraulic parameters. Indeed, for this simulation period, Fig. 10c and a depict equivalent uncer-
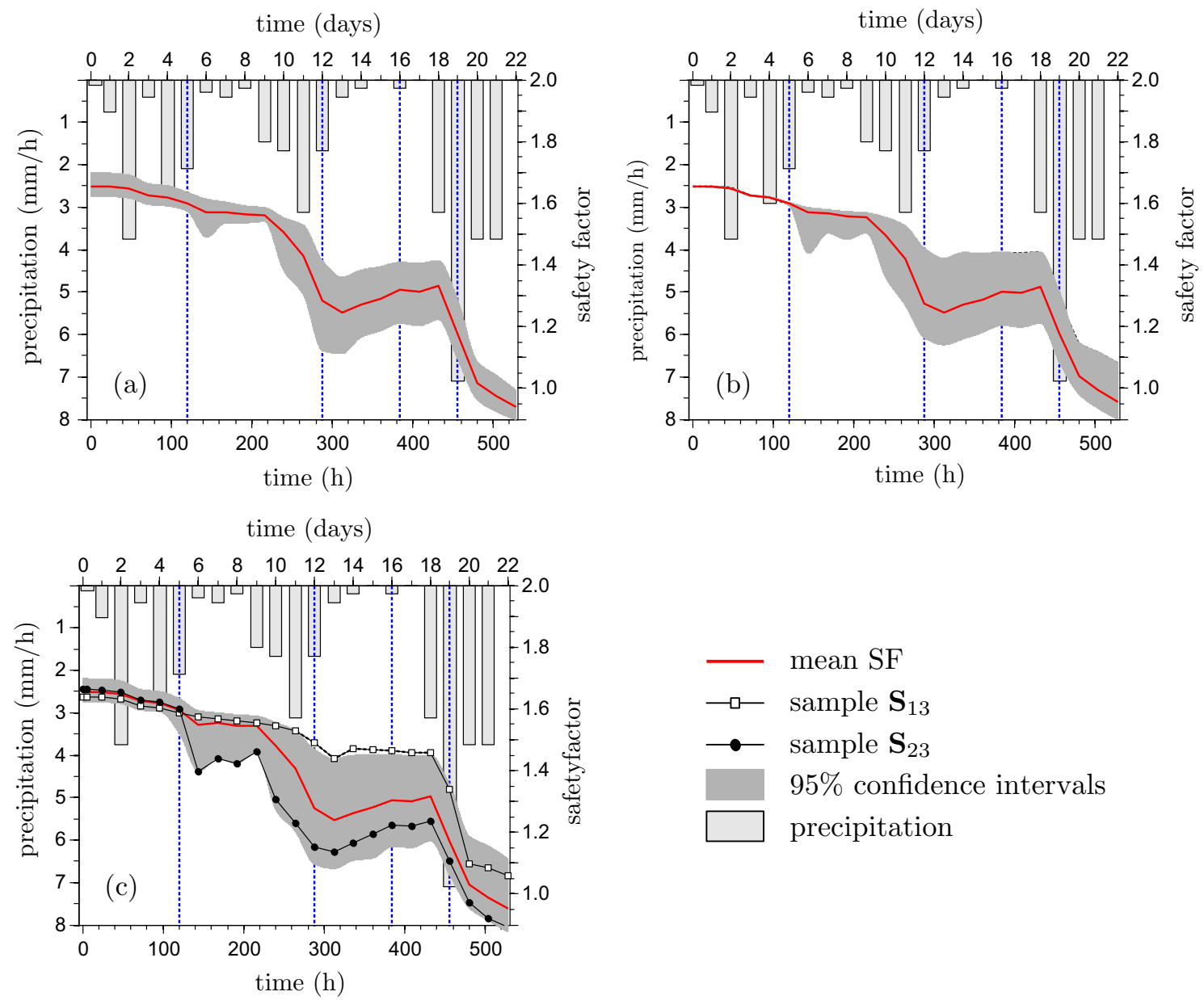

Fig. 10. Uncertainty in the safety factor (SF): $95 \%$ confidence intervals (gray region) and the mean SF (red line) for case study 1 (a), case study 2 (b) and case study 3 (c), are

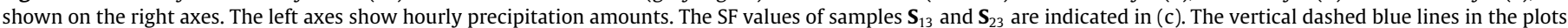

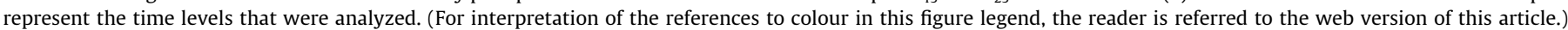


tainty limits. After this time, the multivariate normal prior distribution of the soil hydraulic parameters also affects the confidence intervals of the SF, which are now wider than those of the first two case studies. Notice also the relatively large differences between the SF traces of samples $\boldsymbol{S}_{13}$ and $\boldsymbol{S}_{23}$. These two realizations differ substantially in their assessment of slope stability after the second storm event, and will be investigated in more detail later.

\subsection{Pressure head and failure zone dynamics}

We now investigate how uncertainty in the bedrock depth and soil hydraulic parameters affects pressure head dynamics within the hillslope interior and the failure zones at collapse. Fig. 11 depicts graphically for samples $\boldsymbol{S}_{13}$ (top part) and $\boldsymbol{S}_{23}$ (bottom part) the simulated pressure values at $t=5,12,16$ and 19 days (left-toright) at the soil-bedrock interface (top panels) and along cross section AA' (middle panels). The two bottom panels in both graphs display the velocity vectors at collapse. The samples $\mathbf{S}_{13}$ and $\mathbf{S}_{23}$ exhibit contrasting bedrock topographies (previously depicted in Fig. 9) and soil hydraulic parameter values (listed in Tables 4 and 5). The snapshots from left to right match exactly the times of the vertical dashed blue lines in Fig. 10 and characterize different saturation conditions of the soil-mantle in response to the successive rainfall events. To simplify graphical interpretation, the pressure head values share a common color bar. We first discuss the results of sample $\boldsymbol{S}_{13}$ displayed in the top three panels, followed by those of $\mathbf{S}_{23}$ in the bottom three panels.
The top panel of four plots of Fig. 11a displays simulated pressure heads of sample $\mathbf{S}_{13}$ at the soil-bedrock interface. Initially, at $t=5$ days, the soil-bedrock interface appears almost entirely unsaturated, with the exception of a small area of saturation at the bedrock surface in the middle part of the hillslope. This saturation condition is a leftover of the one-year spin-up period and not caused by the first storm event. In fact, the yellowish-green color is dominant which indicates negative $\psi$ values for large portions of the soil-bedrock interface. Results show that the size of the saturated area increased slowly and upward along the drainage channel during the next three time snapshots in response to antecedent rainfall. This finding is not surprising as moisture contents are expected to increase most in shallow regions [29], where the distance to the impermeable layer is relatively small, thus causing a rapid build-up of infiltrated rainwater. Note that the pressure head values within the saturated areas of the soilbedrock interface tended to increase between $t=5$ and $t=16$ days (darker blue).

While the top panel of Fig. 11a highlights important changes to the extent of the saturated zone at the soil-bedrock interface, the middle panel visualizes the evolution of the saturated area along cross section AA'. At $t=5$ days the soil is mostly unsaturated, except for a small area of the transect where the regolith is thinnest. After the second storm ceased, at $t=12$ days, the antecedent rainfall had caused the area of saturation of $\mathbf{A A}^{\mathbf{A}}$ to expand from the sideslope to the base. This area remained saturated until at least the last snapshot at $t=19$ days. Note that near-saturated zones

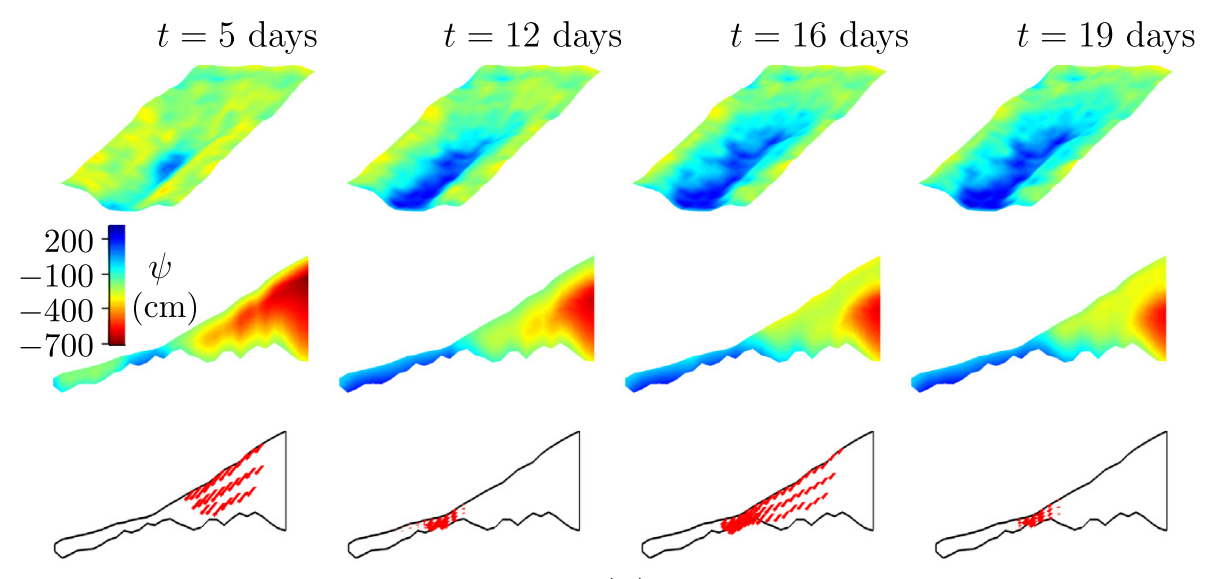

(a)
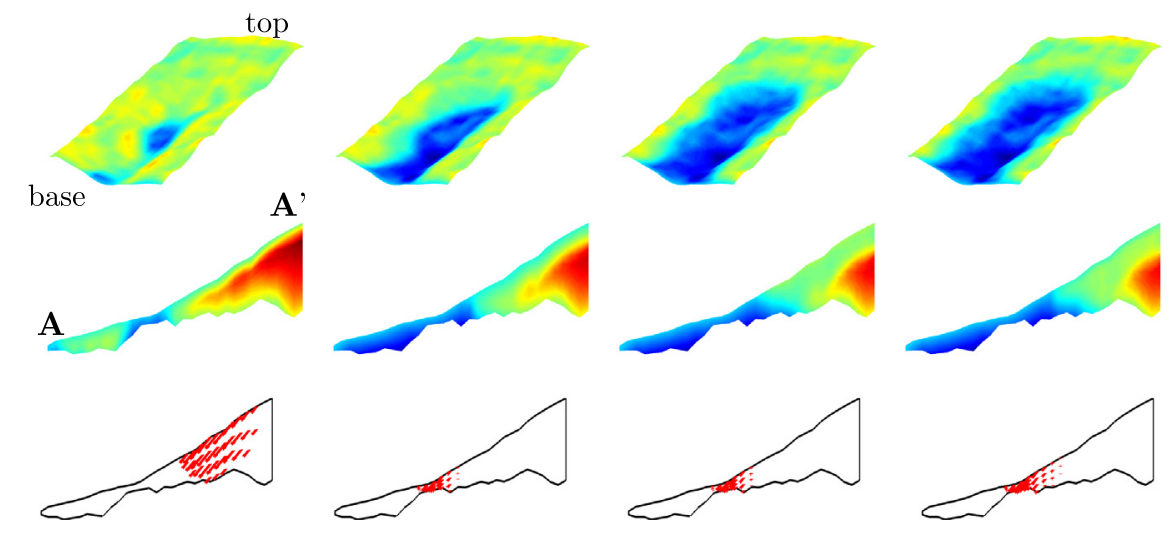

(b)

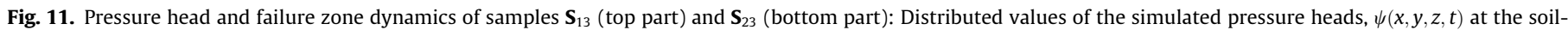

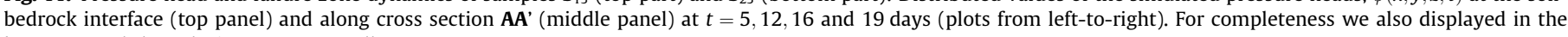
bottom panel the velocity vectors at collapse. 
(light blue areas) developed initially only at the soil-bedrock interface.

The bottom panel of Fig. 11a presents a two-dimensional projection (cross section $\mathbf{A} \mathbf{A}^{\prime}$ ) of the velocity vectors of sample $\mathbf{S}_{13}$ at collapse. The four snapshots in time, as derived from NLA, visualize the possible collapse of the hillslope under different saturation conditions [49]. At $t=5$ days the velocity vectors indicate an approximately circular failure surface at the hilltop. The soil moisture conditions at this time were clearly unsaturated (see middle panel). In the collapse region, topographic gradients were relatively high, with failure occurring due to loss of suction (to be discussed in more detail later). At the end of the second storm event, at $t=12$ days, the shallow soil of the sideslope had become fully saturated, thereby inducing failure in the region of minimum regolith thickness. Then, after a few drier days at $t=16$ days, the velocity vectors extended uphill to areas with the highest topographic gradients near the hilltop. Subsequently, at $t=19$ days, after two more days of rainfall (third storm), the failure zone concentrated again on the thin regolith zone of the sideslope.

The results of sample $\mathbf{S}_{23}$ in the bottom three panels appear very similar to those presented previously for $\mathbf{S}_{13}$ but with two main exceptions. First, the pressure head values at the soil-bedrock interface demonstrate an enlarged area of saturation which covered a much larger portion of the drainage channel and the sideslope. This is most evident in the snapshots of the top and middle panels at $t=16$ and $t=19$ days, and can be explained in part by the much lower saturated conductivity of sample $\mathbf{S}_{23}$ $\left(K_{\mathrm{s}}=0.76 \mathrm{~cm} / \mathrm{h}\right)$ compared to $\mathrm{S}_{13}\left(K_{\mathrm{s}}=4.32 \mathrm{~cm} / \mathrm{h}\right)$. The lower conductivity limits rainfall infiltration, thereby promoting nearsaturated conditions at the hilltop and enhanced storage of water along the sideslope and base (see middle panel in Fig. 11b at $t=12$ days). This enlarged area of saturation can be explained further by the bedrock topography of sample $\mathbf{S}_{23}$, which differs in two important ways from $\mathbf{S}_{13}$. The deeper mantle at the base of the hillslope acts as a storage area for water [29], with higher values of the soil water pressure head, particularly at the soil-bedrock interface. The thinner soils upslope from the inflection point to the hilltop expand uphill the area of saturation to cover a larger portion of

\section{time (days)}

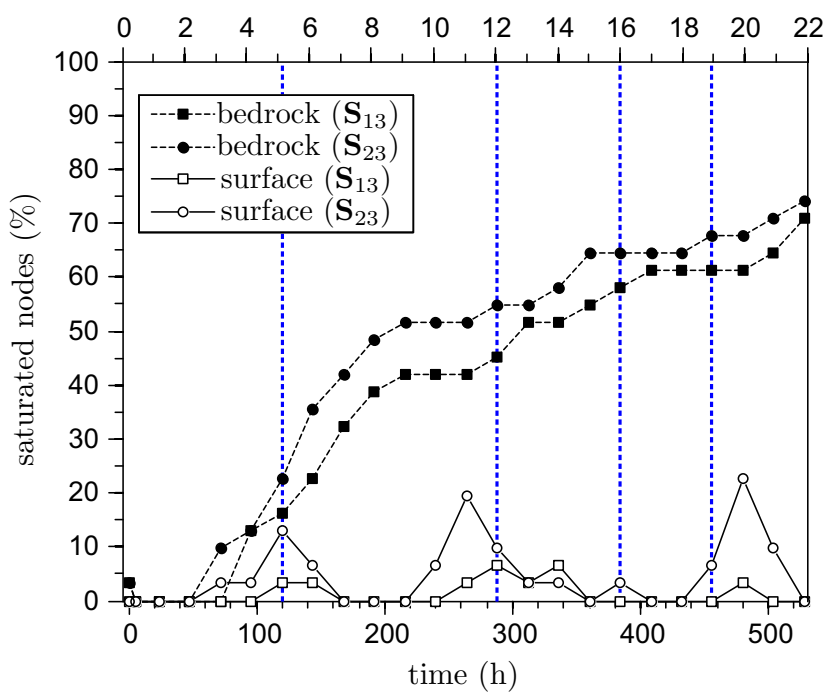

Fig. 12. Time series plot of the percentage (\%) of saturated nodes at the soil-bedrock interface (solid symbols) and at the soil surface (open symbols) of transect $\mathbf{A A}$ during the 22-day experimental period for samples $\mathbf{S}_{13}$ (squares) and $\mathbf{S}_{23}$ (circles). The two realizations differ in terms of their bedrock topography and hydraulic properties of the soil mantle. The four vertical dashed blue lines match the times of the snapshots depicted previously in Fig. 11. the drainage channel. Second, the collapse vectors (red arrows in bottom panel) of $\mathbf{S}_{23}$ at $t=16$ days do not extent to the hilltop as is the case for sample $\boldsymbol{S}_{13}$ but remain confined to a small area of the soil mantle closest to the underlying bedrock. This finding is best understood by considering more closely the pressure head distributions and flow patterns within the slope interior and failure zone.

The differences in the extent of saturated area of samples $\mathbf{S}_{13}$ (squares) and $\boldsymbol{S}_{23}$ (circles) are illustrated in Fig. 12, which presents traceplots of the fraction (expressed as percentage, \%) of saturated nodes at the soil-bedrock interface (solid symbols) and at the soil surface (open symbols) during the 22-day study period. The simulated traces confirm our findings of Fig. 11 in that sample $\mathbf{S}_{23}$ exhibited the largest fraction of saturated nodes at the soilbedrock interface as a consequence of its relatively low saturated conductivity and thin soil mantle in the upper part of the hillslope. The low saturated conductivity of the soil mantle of $\mathbf{S}_{23}$ has important consequences since it slows down the vertical infiltration of rainwater, thereby leading to saturated conditions of a significant fraction of the surface nodes during intense storm events. In the days after each storm event, the saturated surface nodes of $\mathbf{S}_{23}$ dry slowly as water moves to deeper nodes within the soil mantle. In comparison, far fewer (surface) nodes of sample $\mathbf{S}_{13}$ achieved saturated conditions during the course of our 22-day rainfall record due to the higher saturated conductivity of the soil mantle.

We next investigated in more detail the pressure head values within the failure zone of our hillslope. The failure zone may migrate as a result of the variable moisture state of the soil mantle. We used the velocity vectors of Fig. 11 (bottom two panels) to delineate the FE nodes of the evolving failure zones of samples $\mathbf{S}_{13}$ and $\mathbf{S}_{23}$. Fig. 13 shows a plot of their mean pressure head, $\bar{\psi}_{\mathrm{f}}$, during the 22-day rainfall recorded, marked by open squares $\left(\mathbf{S}_{13}\right)$ and solid circles $\left(\mathbf{S}_{23}\right)$ symbols. The simulated trajectories provide further insight into the impact of the soil hydraulic properties (notably the saturated conductivity) and bedrock surface topography on slope stability. The trajectories of the two samples differ substantially, yet demonstrate the steadily increasing amounts of water being stored in their respective failure zones. At the end of the simulation, both samples simulate positive mean pressure

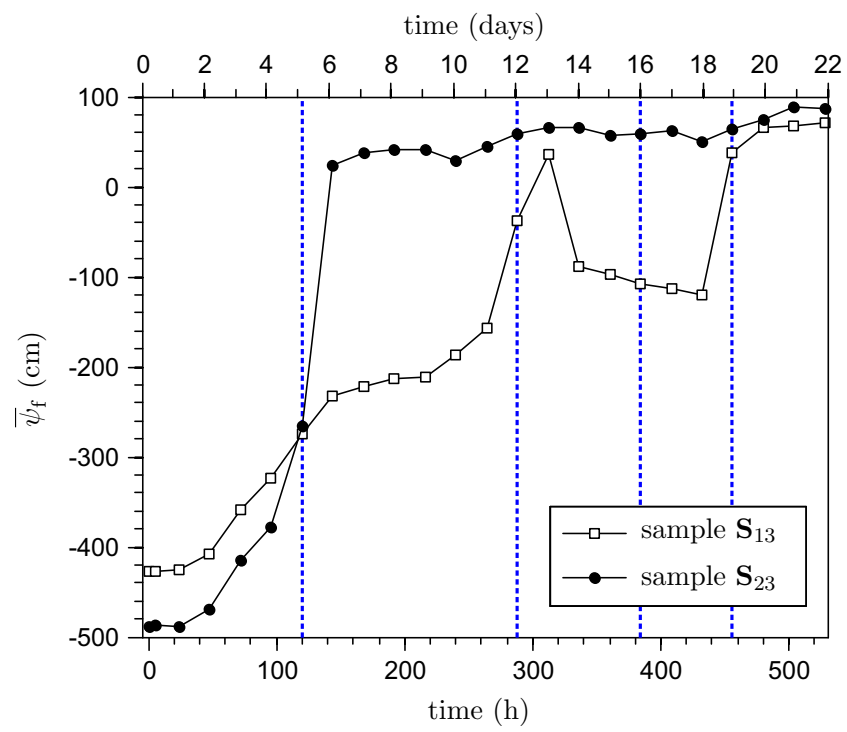

Fig. 13. Evolution of the mean pressure head, $\bar{\psi}_{\mathrm{f}}$, in the failure zones of samples $\mathbf{S}_{13}$ (open squares) and $\mathbf{S}_{23}$ (solid circles) for transect $\mathbf{A} \mathbf{A}^{\prime}$ of our hillslope. The vertical dashed blue lines signify the previously analyzed simulation times. (For interpretation of the references to colour in this figure legend, the reader is referred to the web version of this article.) 
heads due to the large rainfall depths of the three consecutive storm events. In general, the mean pressure head of the failure zone increases in response to rainfall infiltration during and/or immediately after a storm event, and remains constant or decreases somewhat during drier days. The first storm between days 1 and 6 of the 22-day hyetograph may have been sufficient to saturate the nodes of the failure zone of sample $\boldsymbol{S}_{23}$ as illustrated by the simulated positive mean pressure heads at $t=6$ days. The second storm event was needed to saturate the nodes of the failure zone of $\boldsymbol{S}_{13}$, with the mean pressure head becoming positive for the first time at $t=13$ days. The next $120 \mathrm{~h}$ after this second storm event barely changed the conditions within the failure zone of $\mathbf{S}_{23}$ with FE nodes that continuing to be saturated as evidenced by the simulated positive pressure heads. During this same 5-day period the mean pressure head of the failure zone of $\mathbf{S}_{13}$ decreased from positive values of about $+40 \mathrm{~cm}$ at $t=13$, the day after the second storm, to negative values of about $-100 \mathrm{~cm}$ at the end of day 17. The rainfall from the third and last storm of the hyetograph between days 18 and 21 had the most impact on sample $\boldsymbol{S}_{13}$ in that the mean pressure head of its failure zone that changed rapidly on day 18 from negative to positive values. The failure zone continued to be saturated during the remaining days of the 22-day record. The mean pressure head of sample $\mathbf{S}_{23}$ was not much affected by the third storm since the nodes of its failure zone were already saturated at $t=18$ prior to the start of this last precipitation event. Altogether, the results of the two samples demonstrate a more rapid build-up of water in the failure zone of sample $\boldsymbol{S}_{23}$, with nodal pressure heads quickly attaining large positive values. As discussed before, this finding is explained by the low conductivity of the soil mantle of $\mathbf{S}_{23}$ at saturation, and thinner depths of its regolith uphill from the inflection point of the hillslope. Nevertheless, both samples simulated a saturated failure zone at the end of the 22-day hyetograph. As previously shown in Fig. 10c, samples $\mathbf{S}_{13}$ and $\mathbf{S}_{23}$ produced SF values that fell within its $95 \%$ ranges. In other words, the two trajectories of Fig. 13 are a plausible characterization of the pressure head values within the failure zone of the hillslope.

In summary, in this section we have used two samples with contrasting permeabilities and bedrock topographies to analyze the spatiotemporal dynamics of saturated areas within the hillslope interior. The transient pore water pressures of these two samples led to different locations and mean pressure heads of the failure zone within the soil. The next section analyzes more closely how regolith depth, bedrock topography and soil hydraulic properties impact the simulated pressure heads, and thus the pore water pressures, of the soil mantle, and their control on the SF of the hillslope.

\subsection{Impact of regolith depth, bedrock topography and soil hydraulic properties on hillslope stability}

The simulations thus far have demonstrated that a deeper soil mantle accelerates the rapid buildup of water (unless saturated conductivity of the soil mantle is low). This finding is not surprising since deeper soils can store more water. Our simulations indeed showed that moisture content will increase most quickly in areas with a shallow bedrock surface, where a temporary water table may developed in response to antecedent rainfall. This finding is in agreement with previous literature [55,29]. Fig. 14 presents scatterplots of the relationship between the depth of the soil mantle (top panel) and the pressure head at the soil-bedrock interface at $t=5,12,16$ and 19 days. The data points pertain to the case studies 1 (sample $\boldsymbol{S}_{11}$, solid squares) and 3 (sample $\mathbf{S}_{13}$, blue triangles). As listed in Table 5 , these samples have the same bedrock surface $\left(\mathbf{H}_{1}\right)$ but different values of the hydraulic parameters. We used Pearson's correlation coefficient, $\rho \in[-1,1]$, to quantify the strength of the relationship between the scatter in each snapshot of Fig. 14. The stronger the correlation between the variables, the closer the value of $\rho$ is to -1 or +1 . Note that each scatter plot displays the values of $\rho_{1}$ and $\rho_{3}$ for the samples of case studies $1\left(\mathbf{S}_{11}\right)$ and $3\left(\mathbf{S}_{13}\right)$, respectively. The results in the top panel of Fig. 14 confirm the presence of a negative relationship between the depth of the regolith layer and the corresponding pressure head at the soil-bedrock interface. Indeed, the larger the depth of the regolith, the lower the value of the pressure head at the bottom of the soil mantle. This is noticeable in the snapshots at all four times. The correlation between bedrock depth and the pressure head of the soil-bedrock interface increased with time for both
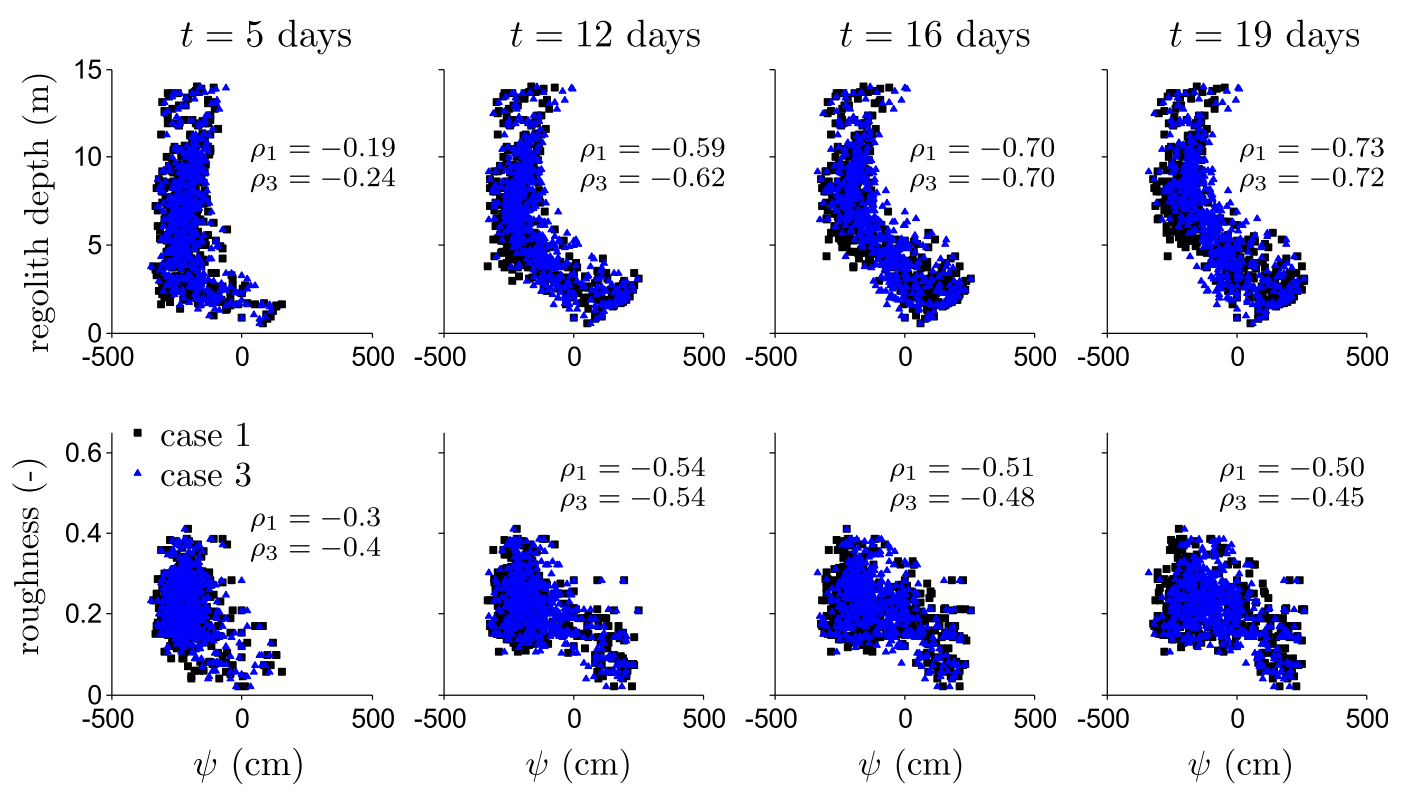

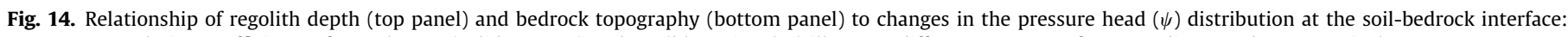
Pearson's correlation coefficients of samples $\mathbf{S}_{11}$ (solid squares) and $\mathbf{S}_{13}$ (blue triangles) illustrate different patterns of case studies 1 and 3, respectively. 
samples during our 22-day study. Nevertheless, the scatter appears somewhat complicated as reflected by the banana-shaped correlation patterns. This suggests that the pressure head at the bedrocksoil interface may be controlled in part by factors other than only the depth of the overlying soil mantle.

Small depressions in the bedrock surface (concave or planar areas) are known to impact the storage, distribution, and movement of water. For example, Liang and Uchida [23] contend that subsurface saturation is governed by three variables, i.e., slope gradient, contributing area, and topographic wetness index. We tested this hypothesis by characterizing the roughness of the bedrock surface using the index proposed by [56]. The bottom panel of Fig. 14 summarizes the results of our analysis. The plots display the roughness of the bedrock topography as a function of the pressure head at the soil-bedrock interface. In general, the larger the value of the bedrock roughness, the larger the variations in bedrock topography of neighboring cells or nodes. Per definition, a flat surface will have a roughness index of zero. The four scatter plots in the bottom panel demonstrate the presence of a negative relationship between bedrock roughness and the pressure head at the soilbedrock interface. The larger the variations in bedrock topography, the lower the pressure head values at the soil-bedrock interface. The strength of this relationship does not change much in time, with correlation coefficients that are very similar for both samples (i.e., $\mathbf{S}_{11}$ and $\mathbf{S}_{13}$ ). We conclude that the pressure head at the soilbedrock interface is moderately affected by the shape of the underlying bedrock surface. The pressure head distribution of the soil mantle hence is not only controlled by regolith thickness but also by small-scale variability of the bedrock topography which affects water flow and redistribution.

We next analyzed how the soil hydraulic parameters $\mathbf{p}=\left\{\theta_{\mathrm{s}}, \theta_{\mathrm{r}}, \alpha, n, K_{\mathrm{s}}\right\}$ control slope stability. Fig. 15 presents two-
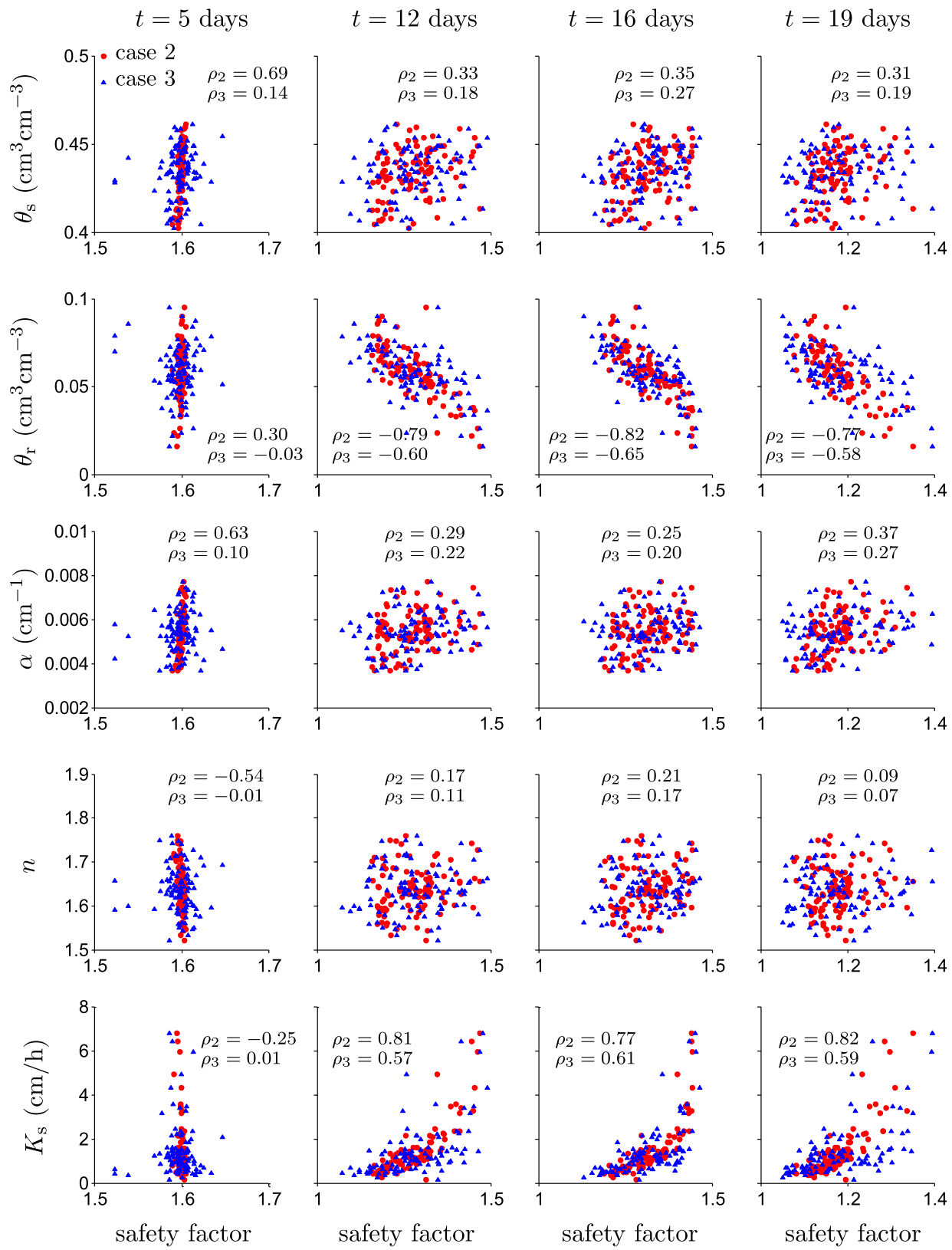

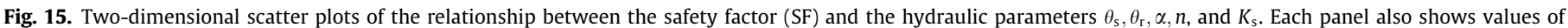

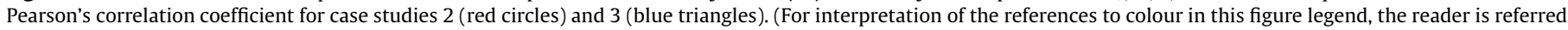
to the web version of this article.) 
dimensional scatter plots of relationships between $\mathbf{p}$ and the SF for case studies 2 (sample $\mathbf{S}_{12}$, red circles) and 3 (sample $\mathbf{S}_{13}$, blue triangles). Note that these case studies differ only in terms of the bedrock surface used in the simulations (Table 5). Correlation coefficients for case studies $2\left(\rho_{2}\right.$, sample $\left.\mathbf{S}_{12}\right)$ and $3\left(\rho_{3}\right.$, sample $\mathbf{S}_{13}$ ) are indicated in each plot. As shown, at $t=5$ days, the SF was not affected by any of the soil hydraulic parameters, certainly not for case study 2, thus suggesting a lack of initial control of the hydraulic properties on slope stability. This finding is consistent with the results of Fig. 10b. The third case study $\left(\mathbf{S}_{13}\right)$ also showed a negligible correlation between the soil hydraulic parameters and the SF. Since both samples use the same hydraulic parameters of the soil mantle, the scatter of case study 3 is due to the use of a different bedrock surface. The scatter is persistent, and visible in the snapshots at all four times. As illustrated in Fig. 15, the soil hydraulic parameters, $\theta_{\mathrm{r}}$ and $K_{\mathrm{s}}$ are strongly correlated with SF in case study 2 and moderately correlated in the case study 3 . The negative feedback between $\theta_{\mathrm{r}}$ and $K_{\mathrm{s}}$ was previously listed in Table 2 . It seems that the SF increases for larger values of the saturated hydraulic conductivity, $K_{\mathrm{s}}$, of the soil mantle. The results in Sec-

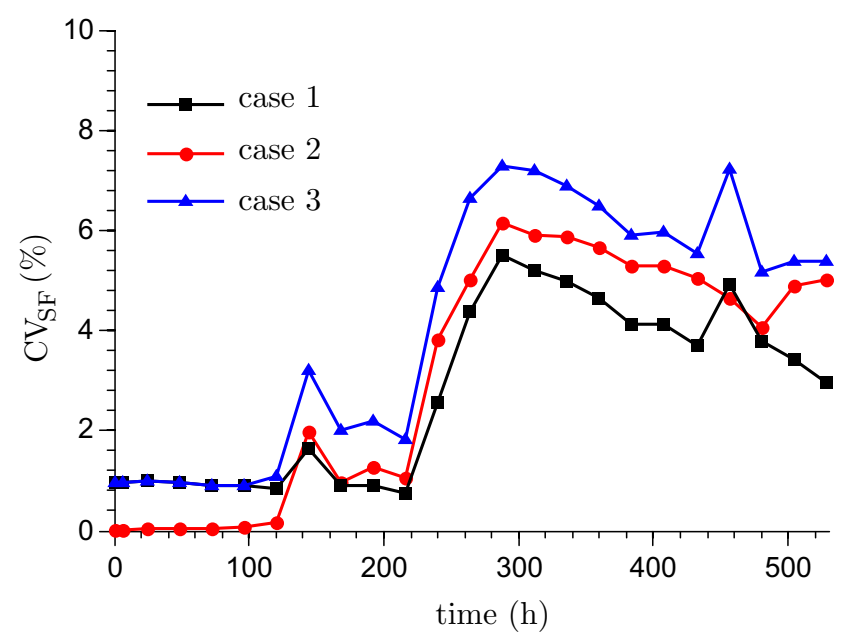

Fig. 16. The coefficient of variation of the safety factor $\left(\mathrm{CV}_{\mathrm{SF}}\right)$ for the three different case studies. tion 5.2 indicated that the less permeable soil mantle induces zones of positive pore pressures at the more steeper zones of the hillslope, thereby reducing the SF. On the other hand, the more permeable soil mantle could increase drainage to the soilbedrock interface, and thus cause water to eventually move laterally to the drainage channel. This observation is in agreement with Lanni et al. [55]. Hence, the planar (saturated) regions of the drainage channel are less susceptible to slope failure, thus leading to a higher SF. This result also agrees with the analysis presented in Fig. 11.

Based on the findings of Figs. 14 and 15, we suggest that the uncertainty in the SF during storm events is determined by complex nonlinear interactions between regolith depth, bedrock surface topography and the permeability of the soil mantle. We next address the combined impact of bedrock depth and soil hydraulic parameter uncertainty on the probability of failure of the hillslope.

\subsection{Probability of failure}

Fig. 16 provides the coefficient of variation of the safety factor $\left(\mathrm{CV}_{\mathrm{SF}}\right)$ with time for the three case studies. The coefficient of variation is a common and convenient statistical metric because it is dimensionless. The metric is given by the quotient of the standard deviation and the corresponding mean of the ensemble of safety factors, $\mu_{\mathrm{SF}}$. As expected, our results agree well with the confidence intervals for the SF (Fig. 10). During the initial stages of the simulation, $\mathrm{CV}_{\mathrm{SF}}$ for case study 1 (black line in Fig. 16) was dominant, although $\mathrm{CV}_{\mathrm{SF}}$ values appeared rather small (around $1 \%$ ). $\mathrm{CV}_{\mathrm{SF}}$ values for case study 3 (blue line) were in excellent agreement with their values for case study 1 , whereas the second case study (red line) produced negligible values. At $t=120 \mathrm{~h}, \mathrm{CV}_{\mathrm{SF}}$ for case study 3 quickly exceeded the other cases, and remained always higher until the end of simulation. These results confirm the importance of the combined effect of bedrock depth and soil hydraulic parameter uncertainty on probabilistic slope stability analyses. If the various sources of uncertainty are not considered simultaneously, non-conservative $\mathrm{CV}_{\mathrm{SF}}$ may results.

We conclude this section with Fig. 17, which displays histograms of the SF for case studies (a) 1, (b) 2, and (c) 3 derived from our Monte Carlo realizations at $t=19$ days, a few days before the end of the 22-day simulation period. The mean SF is separately
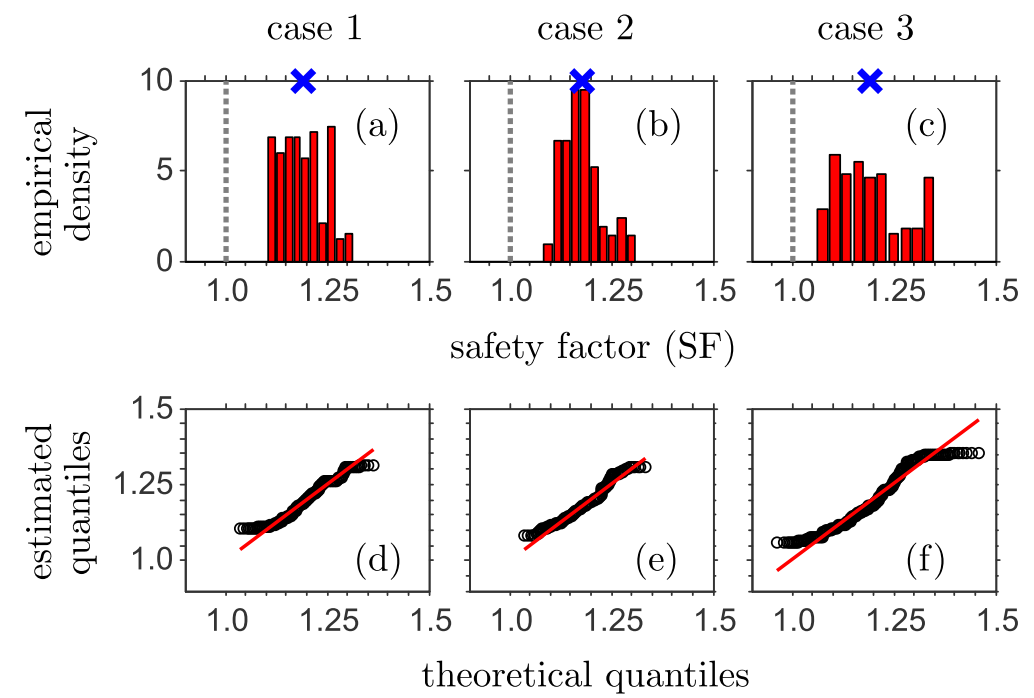

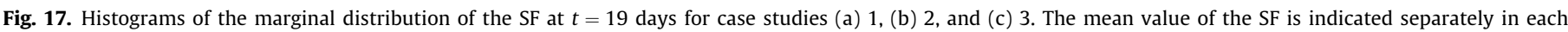

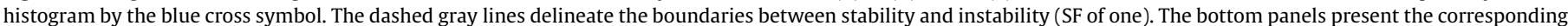

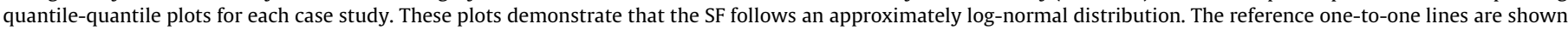
in red. (For interpretation of the references to colour in this figure legend, the reader is referred to the web version of this article.) 
indicated in each graph by the blue cross symbol. The vertical dashed lines in each histogram delineate stability and instability (SF values of unity). As expected, the histogram of the third case study exhibited the most dispersion in response to the combined treatment of bedrock depth and soil hydraulic parameter uncertainty (Figs. 10 and 16).

The shape of the SF distributions (Fig. 17) and the corresponding coefficient of variation (Fig. 16) provide a means for evaluating an alternative measure of safety: the probability of failure, $P_{\mathrm{f}}$. For a given $S F$ distribution, the probability, $\mathbb{P}$, of hillslope failure is reported as $P_{\mathrm{f}}=\mathbb{P}(\mathrm{SF} \leqslant 1)$, i.e., $P_{\mathrm{f}} \in[0,1]$ quantifies the probability that the soil mass will fail (colapse). By assuming the distributions shown in Fig. 17 for the SF, $P_{\mathrm{f}}$ can be estimated from the lognormal reliability index, $\beta_{\mathrm{LN}}$, so that $P_{\mathrm{f}}=1-\Phi\left(\beta_{\mathrm{LN}}\right)$, where $\Phi$ denotes the cumulative distribution function of the standard normal variate [57]. $\beta_{\mathrm{LN}}$ can be calculated as follows [14]:

$\beta_{\mathrm{LN}}=\frac{\ln \left(\mu_{\mathrm{SF}} / \sqrt{1+\mathrm{CV}_{\mathrm{SF}}^{2}}\right)}{\sqrt{\ln \left(1+\mathrm{CV}_{\mathrm{SF}}^{2}\right)}}$.

From Eq. (6), one can note that for a fixed $\mu_{\mathrm{SF}}$, the larger the value of $\mathrm{CV}_{\mathrm{SF}}$, the lower the value of $\beta_{\mathrm{LN}}$, and the larger the probability of failure, $P_{\mathrm{f}}$.

Table 6 reports $P_{\mathrm{f}}$-values for the three case studies at three points in time (i.e., 12,16, and 19 days). While the mean SF (third column) was the same for all case studies, the values of $\mathrm{CV}_{\mathrm{SF}}$ (fourth column) differed noticeably, which caused the values of $P_{\mathrm{f}}$ in the last column to vary between the three case studies. At $t=12$ days, $P_{\mathrm{f}}$ increased an order of magnitude from $0.2 \times 10^{-5}$ to $0.4 \times 10^{-4}$ for case study 1 , to $0.2 \times 10^{-4}$ for case study 2 , and then to $0.2 \times 10^{-3}$ for case study 3 . At $t=16$ days, the $\mu_{\mathrm{SF}}$ values remained rather constant and the already negligible probability of failure of the hillslope has further decreased for each case study, due to smaller values of $\mathrm{CV}_{\mathrm{SF}}$. Finally, at $t=19$ days, the listed $P_{\mathrm{f}}$ 's demonstrate an increased instability of the hillslope, primarily in response to smaller $\mu_{\mathrm{SF}}$ values. Note also that Table 6 indicated the largest probability of failure for case study 3. Indeed, the values of $P_{\mathrm{f}}$ of this study always exceeded their counterparts of the other two studies. This discrepancy is orders of magnitude at $t=12$ and 16 days, but smaller at 19 days. We thus conclude that the joint impact of bedrock depth and soil hydraulic uncertainty impacts significantly the probability of failure.

\section{Discussion}

The integrated hillslope water flow and numerical limit analysis methodology used herein enables explicit treatment of uncertainty in key inputs of slope stability studies of unsaturated soils. We used this Monte Carlo approach and evaluated in this paper the impact of bedrock depth uncertainty (case study 1 ), soil hydraulic uncertainty (case study 2), and their combined uncertainties (case study 3 ) on the stability of a variably-saturated hillslope in Rio de Janeiro, Brazil. We investigated in detail the marginal and joint impact of these uncertainties on distributed pressure head dynamics of the soil mantle, the mean and confidence intervals of the SF, failure mechanisms, and the probability of slope failure. Joint treatment of bedrock depth and hydraulic parameter uncertainty of the soil mantle allowed us to investigate how the balance between regolith depth, bedrock topography and parameters of the variably-saturated flow model can explain complex interactions that drive pore pressures and failure zones. One of the major strengths of our proposed method is that, instead of merely assuming a known and deterministic bedrock surface, one can propagate its uncertainty in geotechnical analysis.

The uncertainty of the bedrock surface was characterized using Bayesian analyses coupled with MCMC simulations. The results allowed us to determine more appropriate confidence limits for the SF. Moreover, having a more accurate bedrock depth map also makes it easier to characterize the impact of soil hydraulic parameters on rainfall-induced landslides. The SF confidence bounds for case study 1 (Fig. 10a) indicate a moderate sensitivity of different stratigraphic profiles when the soil-bedrock interface is predominantly unsaturated. This result is important since past studies indicated that slope failure may occur while some suction is still present in the soil mass [9]. Our simulations revealed that shallow regolith zones may increase pressure heads quickly because the travel distance for the infiltration process is short. However, high positive pore water pressures will only reduce the SF if they develop at bedrock depressions or planar surfaces. Therefore, convex bedrock shapes at the sideslope were effective to drainage and pore pressure dissipation.

The use of a multivariate normal distribution for the van Genuchten-Mualem (VGM) parameters restricts the soil mantle's hydraulic characterization to realistic retention and unsaturated permeability functions as the Monte Carlo sampling honors, via the covariance matrix, the multidimensional correlation structure of the soil hydraulic parameters. This finding is not new and has been previously reported $[18,22,54]$. In practice, however, this approach has not been explored adequately in stability analyses. Our findings suggest that the multivariate normal distributions of the soil hydraulic parameters sampled in a Monte Carlo approach can lead to significant uncertainty in the SF when positive pressure heads start to develop in the soil mantle. Samples from our prior distribution with higher $K_{\mathrm{s}}$ values generally led to more drainage and contributed to the upper bound of the SF uncertainty. Samples with a smaller $K_{\mathrm{s}}$ produced patches of pressure heads beyond the drainage channel, at high-gradient bedrock surface zones, thus reducing the $\mathrm{SF}$.

Table 6

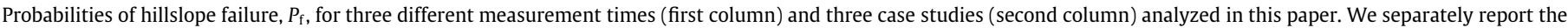
corresponding values of $\mu_{\mathrm{SF}}$ and $\mathrm{CV}_{\mathrm{SF}}$. The listed values of $P_{\mathrm{f}}$ assume a log-normal distribution of the $\mathrm{SF}$ at each time.

\begin{tabular}{|c|c|c|c|c|}
\hline$t$ (days) & Case & $\mu_{\mathrm{SF}}$ & $\mathrm{CV}_{\mathrm{SF}}(\%)$ & $P_{\mathrm{f}}$ \\
\hline \multirow[t]{3}{*}{12} & 1 & 1.29 & 5.50 & $0.2 \times 10^{-5}$ \\
\hline & 2 & 1.28 & 6.14 & $0.4 \times 10^{-4}$ \\
\hline & 3 & 1.29 & 7.28 & $0.2 \times 10^{-3}$ \\
\hline \multirow[t]{3}{*}{16} & 1 & 1.33 & 4.12 & 0 \\
\hline & 2 & 1.31 & 5.28 & 0 \\
\hline & 3 & 1.32 & 5.90 & $0.1 \times 10^{-5}$ \\
\hline \multirow[t]{3}{*}{19} & 1 & 1.19 & 4.93 & $0.2 \times 10^{-3}$ \\
\hline & 2 & 1.18 & 4.65 & $0.2 \times 10^{-3}$ \\
\hline & 3 & 1.19 & 7.23 & $8.8 \times 10^{-3}$ \\
\hline
\end{tabular}


In case study 3 , the combined effect of uncertainties showed an overall increase in the variability of the SF as compared to case studies 1 and 2 (Fig. 16). The large coefficient of variation at the end of the simulations indicated that the joint uncertainty of bedrock depth and the soil hydraulic parameters produced more conservative values of $\mathrm{CV}_{\mathrm{SF}}$. While the mean $\mathrm{SF}$ was about the same for the three case studies (Table 6), the probability of failure for case study 3 was always higher than that for the other two studies. This can be attributed to the interactions between regolith depth, bedrock topography and soil hydraulic parameters as detailed in Section 5.3. These three factors determine patches of saturation that may increase pore pressure and, in turn, influence the SF values derived from NLA. Ignoring uncertainty in bedrock depth and the hydraulic properties of the soil mantle would hence result in overly optimistic, or non-conservative, estimates of the probability of failure.

Despite our efforts to address two important sources of uncertainty on probabilistic analyses of rainfall-induced landslides, some other sources of uncertainty have been conveniently ignored. For instance, some authors have pointed out that landslides are controlled by critical rainfall intensity and duration [7], anisotropic hydraulic conductivity [7,58], slope geometry [2-6], initial saturation $[3,4,7]$, recharge from bedrock [3,58], and strength parameters [11] on landslides. These studies, however, have been restricted to simplified geometries. A large computational burden would be required to analyze all of these variables within a transient three-dimensional framework as proposed herein. In this paper we assumed that soil properties are homogeneous and isotropic and that bedrock is impermeable. This simplification is particularly convenient for large hillslopes for which characterization of subsurface heterogeneity and anisotropy is quite difficult, if not impossible. However, flow through the soil-bedrock interface $[3,23,27]$, rainfall intensity, duration and frequency [7], as well soil macro-permeability [9], if available, should be considered. As shown in this study, the treatment of uncertainty in the bedrock surface is paramount in stochastic modeling of landslides, but other sources of error could be equally important.

\section{Summary and conclusions}

In this paper we presented a stochastic framework to investigate the role of uncertainty in the bedrock surface and hydraulic properties on the geotechnical stability of a variably-saturated, soil-mantled hillslope. This framework couples Monte Carlo simulation of a three-dimensional finite element water flow model of the bedrock-soil domain with numerical limit analysis to compute confidence intervals of the hillslope's safety factor (SF) during some historical period of rainfall events.

Three case studies were used to illustrate our methodology with a regolith depth model of a natural unsaturated hillslope in Rio de Janeiro, Brazil. Our depth-to-bedrock model predicted accurately distributed measurements of the bedrock depth, thus providing a means to quantify, via Bayesian analysis, bedrock topographic uncertainty. The first case study evaluates this uncertainty of the bedrock depth on slope stability using a fixed hydraulic characterization of our soil-hillslope domain. Our results demonstrate that the confidence intervals of the SF are affected by bedrock depth uncertainty, including a moderate variability in the SF during periods in which the soil-bedrock interface is unsaturated. The second case study focused on uncertainty in the soil hydraulic parameters, while keeping the posterior mean bedrock surface derived with Bayesian analysis as a fixed slope geometry. The SF showed negligible variability when the soil mantle was mostly unsaturated, but the confidence intervals increased dramatically with saturation. In the third case study, the combined effects of both sources of uncer- tainties produced broader confidence bounds for the SF. This finding suggests that our Monte Carlo approach improves characterization of hillslope stability and the reliability of the output of hydro-mechanical models, such as safety factors. The larger probability of failure obtained in the third case study further supports this conclusion.

Altogether, the results of our case studies advocate the need for an explicit treatment of bedrock depth uncertainty in hillslope stability analysis studies. Without this treatment, reliability analysis can lead to overly optimistic results by underestimating considerably the actual probability of hillslope failure. Our paper showed how to incorporate bedrock depth uncertainty in geotechnical analyses using a single integrated framework of Monte Carlo simulation, finite element soil water flow modeling and numerical limit analysis.

\section{Conflict of interest}

There is no conflict of interest in this study.

\section{Acknowledgements}

We appreciated the useful comments of the two referees, which helped us to further enhance this manuscript. The authors acknowledge financial support from the Brazilian National Council for Scientific and Technological Development, CNPq. The first author is also grateful to the Highway Department of Espírito Santo State in Brazil (DER-ES) for their help during this research. We would like to thank Alonso Carbono for his help with the compilation of the hillslope water flow model. The MATLAB code of the stochastic slope stability framework presented herein is available upon request from the first author. This includes access to the different codes and scripts used in the three case studies of this paper.

\section{Appendix A. Numerical limit analysis}

We use numerical limit analysis (NLA) to calculate the SF of the variably-saturated hillslope. This Appendix A provides a brief summary of the NLA method as described by Camargo et al. [38]. We refer interested readers to this publication for further details.

\section{A.1. Yield criterion}

In this study we used the Drucker-Prager failure criterion $[59,60]$ as the yield condition. The Drucker-Prager model uses two stress tensor invariants and two material properties. Because we assume plane strain conditions, the material properties can be directly related to the strength parameters of Mohr-Coulomb [38], which are the effective cohesion, $c^{\prime}$, and the friction angle, $\phi^{\prime}$. The shear strength in variably-saturated soils also depends on the soil suction, which affects $c^{\prime}$. We therefore adopt the extended Mohr-Coulomb criterion [61], and make use of the effective stress principle to delineate two independent stress state variables, namely the net normal stress, $\sigma-u_{\mathrm{a}}$, and the suction, $u_{\mathrm{a}}-u_{\mathrm{w}}$ as follows

$$
\begin{aligned}
\tau & =c^{\prime}+\left(u_{\mathrm{a}}-u_{\mathrm{w}}\right) \tan \phi_{\mathrm{b}}+\left(\sigma-u_{\mathrm{a}}\right) \tan \phi^{\prime} \\
& =c_{\mathrm{ap}}+\left(\sigma-u_{\mathrm{a}}\right) \tan \phi^{\prime},
\end{aligned}
$$

where $u_{\mathrm{a}}\left(\mathrm{MT}^{-2} \mathrm{~L}^{-1}\right)$ and $u_{\mathrm{w}}\left(\mathrm{MT}^{-2} \mathrm{~L}^{-1}\right)$ signify the air pressure in the voids and the pore water pressure, respectively, $\phi_{\mathrm{b}}\left({ }^{\circ}\right)$ is a proxy (called angle) for the rate of change in matric suction, while $\sigma$ $\left(\mathrm{MT}^{-2} \mathrm{~L}^{-1}\right)$ represents the total stress. The first two terms at the right-hand-side of Eq. (A.1) measure the combined effects of soil cohesion and soil suction on the shear strength. The sum of these 
two terms is equivalent to the apparent cohesion, $c_{\mathrm{ap}}$. The parameters $c_{\mathrm{ap}}$ and $\phi^{\prime}$ are thus related to the Drucker-Prager soil material.

\section{A.2. Optimization problem}

The collapse factor, $\lambda$, was evaluated by imposing on the statically admissible stress field, $\boldsymbol{\sigma}^{i}=\left\{\sigma_{x x}, \sigma_{y y}, \sigma_{z z}, \tau_{x y}, \tau_{y z}, \tau_{x z}\right\}^{T}$ of dimension $1 \times 6$ (where $T$ denotes transpose), constraints of equilibrium throughout the hillslope domain and the yield criterion of Drucker-Prager. This is equivalent to the following deterministic and convex optimization problem

$$
\begin{aligned}
& \text { maximize } \lambda \\
& \text { subjet to } \mathbf{G} \cdot \boldsymbol{\sigma}=\lambda \mathbf{f} \\
& g\left(\boldsymbol{\sigma}^{i}\right) \leqslant 0, \quad i=1, \ldots, N_{\mathrm{e}} \quad \text { yield criterion, }
\end{aligned}
$$

where $\mathbf{G}$ denotes the $3 N_{n} \times 6 N_{e}$ equilibrium matrix of the $N_{\mathrm{n}}$ nodes and $N_{\mathrm{e}}$ elements of the finite-element mesh of the hillslope, $\mathbf{f}$ is the $3 N_{n} \times 1$ vector of body forces associated with the weight of the soil material at each element of the mesh, and $g\left(\sigma^{i}\right)$ signifies the yield condition.

The convexity of the collapse load optimization problem of Eq. (A.2) can be exploited using second-order cone programming $[49,51]$. In this approach, the $6 N_{e} \times 1$ vector $\boldsymbol{\sigma}$ is transformed linearly into an auxiliary vector, $\rho$, composed of stresses in a conic quadratic space [51]

$\boldsymbol{\rho}=\mathbf{D} \cdot \boldsymbol{\sigma}+\mathbf{d}$,

where the matrix $\mathbf{D}$ and the vector $\mathbf{d}$ store the coefficients of the Drucker-Prager yield criterion. For each element of the mesh, $\mathbf{D}^{i}$ is a $6 \times 6$ matrix, while vector $\mathbf{d}^{i}$ has dimensions $6 \times 1$. In a conic quadratic form, the collapse factor optimization problem now reads [38]

$$
\begin{array}{ll}
\operatorname{maximize} & \lambda \\
\text { subjet to } & \mathbf{G} \cdot\left(\mathbf{D}^{-1} \cdot \boldsymbol{\rho}-\mathbf{D}^{-1} \cdot \mathbf{d}\right)=\mathbf{f}+\lambda \mathbf{f}_{\mathrm{h}}, \\
& \boldsymbol{\rho}^{i} \in \mathcal{K}, \quad i=1, \ldots, N_{\mathrm{e}}
\end{array}
$$

where the $3 N_{n} \times 1$ vector $\mathbf{f}_{\mathrm{h}}$ stores the external nodal forces acting on the soil mass of the hillslope, (net effect of horizontal and fictitious body forces), and where each auxiliary (elementary) vector, $\boldsymbol{\rho}^{i}$, is restricted to the conic quadratic set, $\mathcal{K}$. We solved numerically for the collapse factor in Eq. (A.4) using the MOSEK optimization toolbox in MATLAB [62]. This toolbox gives users access to a large array of powerful optimization methods for solving a wide range of minimization problems, including second-order conic quadratic problems. A particularly strong point of MOSEK is its state-of-theart interior-point optimizer, which allows for rapid solutions of high-dimensional continuous linear, quadratic and conic optimization problems. Note that it is numerically convenient to use $\mathbf{f}_{\mathrm{h}}$ in the equilibrium condition as this simplifies considerably our calculations of the SF. Please refer to [38] for a detailed description of the NLA method used in our study.

\section{A.3. Boundary conditions}

Once the collapse load optimization problem has been defined mathematically, one still has to define the boundary conditions of the hillslope being studied. The boundary conditions appear in the equilibrium matrix, $\mathbf{G}$, and the vectors $\mathbf{f}$ and $\mathbf{f}_{\mathrm{h}}$ for the bedrock, lateral, downslope, and upslope faces, respectively. As detailed in Fig. $2 \mathrm{~b}$, we used zero velocities in the $u, v$ and $w$ directions.

\section{A.4. Safety factor (SF)}

A shear strength reduction technique was used to compute the SF of the hillslope during our 22-day rainfall record. This method decreases iteratively the values of the strength parameters, $c_{\mathrm{ap}}$ and $\phi^{\prime}$, via a reduction factor until the collapse factor, $\lambda$, approaches zero. We invoked Newton's method to solve for the root of the reduction factor at many different simulation times [38]. This resulted in a 22-day SF record of the variably-saturated hillslope. To maximize search efficiency of Newton's method, we initialized the reduction factor with the root (its optimized solution) of the previous simulation time.

\section{Appendix B. Characterization of bedrock topographic uncertainty}

Depth to bedrock is a key variable in slope stability studies but difficult to measure directly in practice as hillslope interiors are poorly accessible. Instead, we generated many different plausible relizations of the bedrock surface using the calibrated depth-tobedrock (DTB) model of [33]. The approach we describe below accounts explicitly for DTB parameters and model uncertainty, and delivers on the promise of [33] that (page 3085) "The posterior prediction uncertainty of the DTB model can be propagated forward through hydromechanical models to derive probabilistic estimates of factors of safety." Indeed, one can treat depth to bedrock as a probabilistic variable and use Monte Carlo simulation with many different bedrock topographies to quantify uncertainty in the estimates of slope stability.

To clarify our approach, we write the DTB model, $\mathcal{F}(\cdot)$ as a simple nonlinear regression function

$\mathbf{H}=\mathcal{F}(\boldsymbol{\delta})$

which returns a $K \times L$ matrix of simulated bedrock depths, $\mathbf{H}$, for parameter values, $\boldsymbol{\delta}=\left\{\delta_{1}, \ldots, \delta_{d}\right\}$. The $K$ rows and $L$ columns signify different dimensions of $\mathbf{H}$, i.e., the $x$ and $y$ coordinates of the hillslope. We can now estimate the values of the $d$ parameters of the regression function via Bayesian inference with the DREAM algorithm [36,37]. This results in a large sample of $M$ parameter vectors, also called posterior solutions, whose simulated bedrock surfaces best explain $N$ distributed measurements of the bedrock depth. These posterior parameter vectors are stored in a $M \times d$ matrix, $\boldsymbol{\Delta}=\left\{\boldsymbol{\delta}_{1}, \ldots, \boldsymbol{\delta}_{M}\right\}$, and their corresponding matrices of the bedrock depth in a three-dimensional array, $\hbar$, of size $K \times L \times M$, and thus $\hbar=\left\{\mathbf{H}_{1}, \ldots, \mathbf{H}_{M}\right\}$. The third dimension of $\hbar$ now stores the $M$ different posterior maps of the bedrock surface. The expectation, $\mathbb{E}(\hbar)$, of these $M$ realizations equates to the posterior mean bedrock depth map simulated by the DTB model. Confidence intervals of this mean map are easily constructed from the different posterior realizations, by sorting from low to high and for each entry of the model output matrix the $M$ simulated bedrock depths. The indexes $0.025 M$ and $0.975 \mathrm{M}$ of each sorted vector constitute the $95 \%$ prediction ranges of the DTB model due to parameter uncertainty. One can derive the total prediction uncertainty of the DTB model by adding to each entry of $\hbar$ a random draw from the model error distribution. This procedure is outlined in the main text. Fig. B.1 displays the mean bedrock depth (red line) and its associated 95\% predictions intervals (blue lines) for cross section AA' of the hillslope using $M=100$ (solid lines), $M=200$ (dashed lines) and $M=1000$ (dotted lines) posterior realizations. The surface topography is indicated separately by the solid black line. The posterior mean bedrock surface and its confidence intervals appear only minimally affected by the choice of $M$. To minimize the computational requirements of the Monte Carlo framework, we therefore did set $M$ at 100 . 


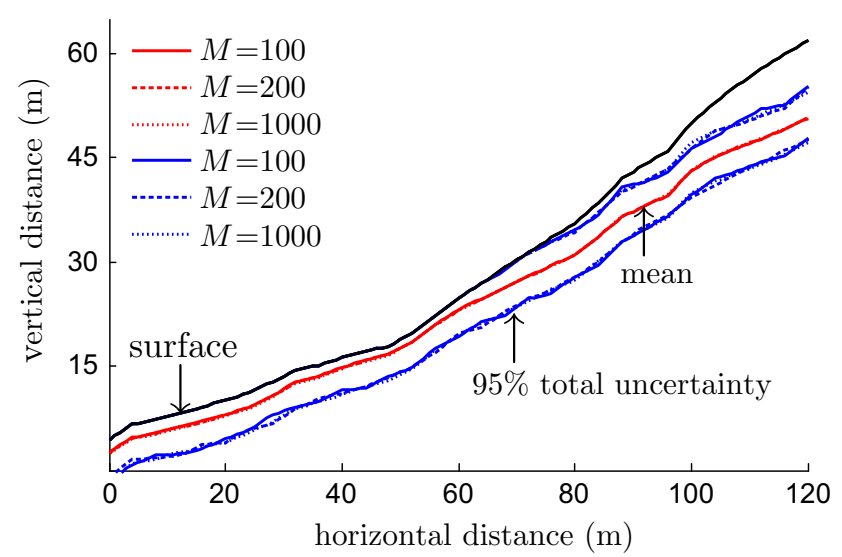

Fig. B.1. Two-dimensional plot of the posterior mean bedrock topography (red line) and the $95 \%$ confidence intervals due to DTB model and parameter uncertainty (blue lines) of transect $\mathbf{A} \boldsymbol{A}^{\prime}$ of the hillslope using $M=100$ (solid lines), $M=200$ (dashed lines) and $M=1000$ (dotted lines) posterior solutions. The solid black line depicts the surface topography. (For interpretation of the references to colour in this figure legend, the reader is referred to the web version of this article.)

\section{References}

[1] Rempe DM, Dietrich WE. A bottom-up control on fresh-bedrock topography under landscapes. Proc Natl Acad Sci 2014;111(18):6576-81. http://dx.doi.org/ 10.1073 /pnas.1404763111.

[2] Zhang Y, Chen G, Zheng L, Li Y, Zhuang X. Effects of geometries on threedimensional slope stability. Can Geotech J 2013;50(3):233-49. http://dx.doi. org/10.1139/cgj-2012-0279.

[3] Vargas Jr EA, Velloso RC, de Campos TMP, Filho LMC. Saturated-unsaturated analysis of water flow in slopes of Rio de Janeiro, Brazil. Comput Geotech 1990;10(3):247-61. http://dx.doi.org/10.1016/0266-352X(90)90038-W.

[4] Mukhlisin M, Taha M, Kosugi K. Numerical analysis of effective soil porosity and soil thickness effects on slope stability at a hillslope of weathered granitic soil formation. Geosci J 2008;12(4):401-10. http://dx.doi.org/10.1007/s12303008-0039-0.

[5] Catani F, Segoni S, Falorni G. An empirical geomorphology-based approach to the spatial prediction of soil thickness at catchment scale. Water Resour Res 2010;46(5). http://dx.doi.org/10.1029/2008WR007450.

[6] Fan L, Lehmann P, Or D. Effects of soil spatial variability at the hillslope and catchment scales on characteristics of rainfall-induced landslides. Water Resour Res 2016:840-57. http://dx.doi.org/10.1002/2015WR017758.

[7] Ng CWW, Shi Q. A numerical investigation of the stability of unsaturated soil slopes subjected to transient seepage. Comput Geotech 1998;22(1):1-28. http://dx.doi.org/10.1016/S0266-352X(97)00036-0.

[8] Zhang LL, Zuo ZB, Ye GL, Jeng DS, Wang JH. Probabilistic parameter estimation and predictive uncertainty based on field measurements for unsaturated soil slope. Comput Geotech 2013;48:72-81. http://dx.doi.org/10.1016/ i.compgeo.2012.09.011.

[9] El-Ramly H, Morgenstern NR, Cruden DM. Probabilistic assessment of stability of a cut slope in residual soil. Géotechnique 2005;55(1):77-84. http://dx.doi. org/10.1680/geot.2005.55.1.77.

[10] François B, Tacher L, Bonnard C, Laloui L, Triguero V. Numerical modelling of the hydrogeological and geomechanical behaviour of a large slope movement: the Triesenberg landslide (Liechtenstein). Can Geotech J 2007;44(7):840-57. http://dx.doi.org/10.1139/t07-028.

[11] Griffiths DV, Huang J, Fenton GA. Influence of spatial variability on slope reliability using 2-D random fields. J Geotech Geoenviron Eng 2009;135 (10):1367-78. http://dx.doi.org/10.1061/(ASCE)GT.1943-5606.0000099.

[12] Cho SE, Lee SR. Instability of unsaturated soil slopes due to infiltration. Comput Geotech 2001;28(3):185-208. http://dx.doi.org/10.1016/S0266-352X(00) 00027-6.

[13] Tsaparas I, Rahardjo H, Toll DG, Leong EC. Controlling parameters for rainfallinduced landslides. Comput Geotech 2002;29(1):1-27. http://dx.doi.org/ 10.1016/S0266-352X(01)00019-2.

[14] Duncan JM, Wright SG. Soil strength and slope stability. New York: John Wiley \& Sons; 2005.

[15] Christian JT, Ladd CC, Baecher GB. Reliability applied to slope stability analysis. J Geotech Eng-ASCE 1994;120(12):2180-207. http://dx.doi.org/10.1061/ (ASCE)0733-9410.

[16] Kang F, Han S, Salgado R, Li J. System probabilistic stability analysis of soil slopes using Gaussian process regression with Latin hypercube sampling. Comput Geotech 2015;63:13-25. http://dx.doi.org/10.1016/ j.compgeo.2014.08.010.

[17] Malkawi AIH, Hassan WF, Abdulla FA. Uncertainty and reliability analysis applied to slope stability. Struct Saf 2000;22:161-87. http://dx.doi.org/ 10.1016/S0167-4730(00)00006-0.
[18] Phoon K, Santoso A, Quek S. Probabilistic analysis of soil-water characteristic curves. J Geotech Geoenviron Eng 2010;136(3):445-55. http://dx.doi.org/ 10.1061/(ASCE)GT.1943-5606.0000222.

[19] Wang Y, Cao Z, Au SK. Efficient Monte Carlo simulation of parameter sensitivity in probabilistic slope stability analysis. Comput Geotech 2010;37:1015-22. http://dx.doi.org/10.1016/i.compgeo.2010.08.010.

[20] Zhang LL, Zhang LM, Tang WH. Rainfall-induced slope failure considering variability of soil properties. Géotechnique 2005;55(2):183-8. http://dx.doi. org/10.1680/geot.2005.55.2.183.

[21] Vrugt JA, Diks CGH, Gupta HV, Bouten W, Verstraten JM. Improved treatment of uncertainty in hydrologic modeling: combining the strengths of global optimization and data assimilation. Water Resour Res 2005;41(1). http://dx. doi.org/10.1029/2004WR003059

[22] Scharnagl B, Vrugt JA, Vereecken H, Herbst M. Inverse modelling of in situ soil water dynamics: investigating the effect of different prior distributions of the soil hydraulic parameters. Hydrol Earth Syst Sci 2011;15(10):3043-59. http:/ dx.doi.org/10.5194/hess-15-3043-2011.

[23] Liang WL, Uchida T. Effects of topography and soil depth on saturated-zone dynamics in steep hillslopes explored using the three-dimensional Richards' equation. J Hydrol 2014;510:124-36. http://dx.doi.org/10.1016/j. ihydrol.2013.12.029.

[24] Reid M. Slope instability caused by small variations in hydraulic conductivity. J Geotech Geoenviron Eng 1997;123(8):717-25. http://dx.doi.org/10.1061/ (ASCE) 1090-0241(1997)123:8(717).

[25] Cai F, Ugai K, Wakai A, Li Q. Effects of horizontal drains on slope stability under rainfall by three-dimensional finite element analysis. Comput Geotech 1998;23(4):255-75. http://dx.doi.org/10.1016/S0266-352X(98)00021-4.

[26] Dou H, Han T, Gong X, Zhang J. Probabilistic slope stability analysis considering the variability of hydraulic conductivity under rainfall infiltrationredistribution conditions. Eng Geol 2014;183:1-13. http://dx.doi.org/ 10.1016/i.enggeo.2014.09.005.

[27] Gerscovich DMS, Vargas Jr EA, de Campos TMP. On the evaluation of unsaturated flow in a natural slope in Rio de Janeiro, Brazil. Eng Geol 2006;88(12):23-40. http://dx.doi.org/10.1016/i.enggeo.2006.07.008.

[28] Lanni C, Borga M, Rigon R, Tarolli P. Modelling shallow landslide susceptibility by means of a subsurface flow path connectivity index and estimates of soil depth spatial distribution. Hydrol Earth Syst Sci 2012;16(11):3959-71. http:// dx.doi.org/10.5194/hess-16-3959-2012.

[29] Hopp L, McDonnell JJ. Connectivity at hillslope scale: identifying interactions between storm size, bedrock permeability, slope angle and soil depth. J Hydrol 2009;376:378-91. http://dx.doi.org/10.1016/i.jhydrol.2009.07.047.

[30] Montgomery DR, Dietrich WE, Hefner JT. Piezometric response in shallow bedrock at CB1: implications for runoff generation and shallow landsliding. Water Resour Res 2002;38(12). http://dx.doi.org/10.10029/2001WR001429.

[31] Wang GH, Sassa K. Pore-pressure generation and movement of rainfallinduced landslides: effects of grain size and fine-particle content. Eng Geol 2003;69(1-2):109-25. http://dx.doi.org/10.1016/S0013-7952(02)00268-5.

[32] Kim MS, Onda Y, Kim JK, Kim SW. Effect of topography and soil parameterisation representing soil thicknesses on shallow landslide modelling. Quatern Int 2015;384:91-106. http://dx.doi.org/10.1016/i. quaint.2015.03.057.

[33] Gomes GJC, Vrugt JA, Vargas Jr EA. Toward improved prediction of the bedrock depth underneath hillslopes: Bayesian inference of the bottom-up control hypothesis using high-resolution topographic data. Water Resour Res 2016:52. http://dx.doi.org/10.1002/2015WR018147.

[34] Lee KT, Ho JY. Prediction of landslide occurence based on slope-instability analysis and hydrological model simulation. J Hydrol 2009;375:489-97. http://dx.doi.org/10.1016/i.jhydrol.2009.06.053.

[35] Ho JY, Lee KT, Chang TC, Wang ZY, Liao YH. Influences of spatial distribution of soil thickness on shallow landslide prediction. Eng Geol 2012;124:38-46. http://dx.doi.org/10.1016/i.enggeo.2011.09.013.

[36] Vrugt JA, ter Braak CJF, Clark MP, Hyman JM, Robinson BA. Treatment of input uncertainty in hydrologic modeling: doing hydrology backward with Markov chain Monte Carlo simulation. Water Resour Res 2008;44(12). http://dx.doi. org/10.1029/2007WR006720.

[37] Vrugt JA, ter Braak CJF, Diks CGH, Robinson BA, Hyman JM, Higdon D. Accelerating Markov chain Monte Carlo simulation by differential evolution with self-adaptive randomized subspace sampling. Int J Nonlin Sci Num 2009;10(3):273-90. http://dx.doi.org/10.1002/esp.3423.

[38] Camargo JT, Velloso RQ Vargas Jr EA. Numerical limit analysis of threedimensional slope stability problems at catchment scale. Acta Geotech 2016:1-15. http://dx.doi.org/10.1007/s11440-016-0459-3.

[39] Schaap MG, Leij FJ, van Genuchten MTh. ROSETTA: a computer program for estimating soil hydraulic parameters with hierarchical pedotransfer functions. J Hydrol 2001;251:163-76. http://dx.doi.org/10.1016/S0022-1694(01)004668.

[40] Matthies H, Strang G. The solution of nonlinear finite element equations. Int J Num Meth Eng 1979;14(11):1613-26. http://dx.doi.org/10.1002/ nme.1620141104.

[41] Bathe KJ, Cimento AP. Some practical procedures for the solution of nonlinear finite element equations. Comput Methods Appl Mech Eng 1980;22(1):59-85 http://dx.doi.org/10.1016/0045-7825(80)90051-1.

[42] Gomes GJC, Araujo JP, Vargas Jr EA, Fernandes NF. In-situ regolith depth measurements by DPL tests. In: Proceedings of the XVIII Brazilian conference on soil mechanics and geotechnical engeneering, vol. 1. Belo Horizonte, Brazil; 2016. p. 1-8. doi:http://dx.doi.org/10.20906/CPS/GJ-01-0035. 
[43] Paniconi C, Aldama AA, Wood EF. Numerical evaluation of iterative and noniterative methods for the solution of the nonlinear Richards equation. Water Resour Res 1991;27(6):1147-63. http://dx.doi.org/10.1029/ 91WR00334.

[44] Šimunek, J, Vogel, T, van Genuchten, MTh. The SWMS 2D code for simulating water flow and solute transport in two-dimensional variably saturated media - version 1.21. Research report 132, US Salinity Laboratory, Riverside, California; 1994.

[45] Anderson MP, Woessner WW, Hunt RJ. Applied groundwater modeling. San Diego: Academic Press; 2015.

[46] Rahman MM, Lu M, Kyi KH. Seasonality of hydrological model spin-up time: a case study using the Xinanjiang model. Hydrol Earth Syst Sci Discuss 2016:1-22. http://dx.doi.org/10.5194/hess-2016-316.

[47] van Genuchten MTh. A closed-form equation for predicting the hydraulic conductivity of unsaturated soils. Soil Sci Soc Am J 1980;44(5):892-8. http:/ dx.doi.org/10.2136/sssaj1980.03615995004400050002x.

[48] Mualem Y. A new model for predicting the hydraulic conductivity of unsaturated porous media. Water Resour Res 1976;12(3):513-22. http://dx doi.org/10.1029/WR012i003p00513.

[49] Sloan S. Geotechnical stability analysis. Géotechnique 2013;63(7):531-72. http://dx.doi.org/10.1680/geot.12.RL.001.

[50] Durand AF, Vargas Jr EA, Vaz LE. Applications of numerical limit analysis (NLA) to stability problems of rock and soil masses. Int J Rock Mech Min Sci 2006;43 (3):408-25. http://dx.doi.org/10.1016/j.ijrmms.2005.07.010.

[51] Makrodimopoulos A, Martin CM. Lower bound limit analysis of cohesivefrictional materials using second-order cone programming. Int J Num Meth Eng 2006;66(4):604-34. http://dx.doi.org/10.1002/nme.1567.
[52] Li AJ, Merifield RS, Lyamin AV. Three-dimensional stability charts for slopes based on limit analysis methods. Can Geotech J 2010;47(12):1316-34. http:// dx.doi.org/10.1139/T10-030.

[53] Vieira BC, Fernandes NF. Landslides in Rio de Janeiro: the role played by variations in soil hydraulic conductivity. Hydrol Process 2004;18(4):791-805. http://dx.doi.org/10.1002/hyp.1363.

[54] Vrugt JA, Bouten W, Gupta HV, Hopmans JW. Toward improved identifiability of soil hydraulic parameters: on the selection of a suitable parametric model. Vadose Zone J 2003;2(1):98-113. http://dx.doi.org/10.2136/vzj2003.9800.

[55] Lanni C, McDonnell J, Hopp L, Rigon R. Simulated effect of soil depth and bedrock topography on near-surface hydrologic response and slope stability. Earth Surf Proc Land 2013;38(2):146-59. http://dx.doi.org/10.1002/esp.3267.

[56] Riley SJ, DeGloria SD, Elliot R. A terrain ruggedness index that quantifies topographic heterogeneity. Intermt J Sci 1999;5(1-4):23-7.

[57] Baecher GB, Christian JT. Reliability and statistics in geotechnical engineering. England: John Wiley \& Sons Ltd; 2003.

[58] Leach B, Herbert R. The genesis of a numerical model for the study of the hydrogeology of a steep hillside in Hong Kong. Q J Eng Geol Hydroge 1982;15 (3):243-59. http://dx.doi.org/10.1144/GSL.OJEG.1982.015.03.09.

[59] Drucker DC, Prager W, Greenberg HJ. Extended limit design theorems for continuous media. Quart Appl Math 1952;9:381-9.

[60] Drucker DC, Prager W. Soil mechanics and plastic analysis for limit design. Quart Appl Math 1952;10:157-65.

[61] Fredlund DG, Rahardjo H. Soil mechanics for unsaturated soils. New York: John Wiley \& Sons; 1993.

[62] MOSEK ApS. The MOSEK optimization toolbox for MATLAB manual. Version 7.1 (Revision 28); 2015. <http://docs.mosek.com/7.1/toolbox/index.html>. 